\title{
Comparing forward and inverse models to estimate the seasonal variation of hemisphere-integrated fluxes of carbonyl sulfide
}

\author{
A. J. Kettle ${ }^{1}$, U. Kuhn ${ }^{2}$, M. von Hobe ${ }^{2}$, J. Kesselmeier ${ }^{2}$, P. S. Liss ${ }^{1}$, and M. O. Andreae ${ }^{2}$ \\ ${ }^{1}$ School of Environmental Sciences, University of East Anglia, Norwich, UK \\ ${ }^{2}$ Biogeochemistry Department, Max Planck Institute for Chemistry, Mainz, Germany
}

Received: 16 April 2002 - Published in Atmos. Chem. Phys. Discuss.: 12 June 2002

Revised: 21 October 2002 - Accepted: 22 October 2002 - Published: 14 November 2002

\begin{abstract}
A simple inverse model is proposed to deduce hemisphere-integrated COS flux based on published time series of total column COS. The global atmosphere is divided into two boxes representing the Northern and Southern Hemispheres, and the total column COS data from several stations are used to calculate hemispheric COS loadings. The integrated flux within each hemisphere is calculated as a linear combination of a steady-state solution and time-varying perturbation. The nature of the time-varying perturbation is deduced using two different approaches: an analytic solution based on a cosine function that was fitted to the original total column COS measurement time series and a Simplex optimization with no underlying assumption about the functional form of the total column time series. The results suggest that there is a steady-state COS flux from the Northern to the Southern Hemisphere. There is a seasonal variation superimposed on this flux that in the Southern Hemisphere has a maximum rate of COS input into the atmosphere around January and a maximum rate of COS removal from the atmosphere around August-September. In the Northern Hemisphere, the maximum rate of COS input into the atmosphere is around May-June, and the maximum rate of COS removal is either August or January, depending on which station in the Northern Hemisphere is considered. The results of the inverse model are compared with the outcome of a forward approach on the temporal and spatial variation of the dominant global sources and sinks published earlier. In general, the deduced hemisphere-integrated flux estimates showed good agreement with the database estimates, though it remains uncertain whether COS removal from the atmosphere in the Northern Hemisphere is dominated by plant and soil uptake in the boreal summer or by oceanic uptake in boreal winter.
\end{abstract}

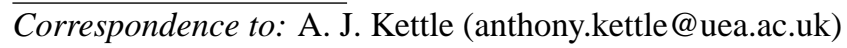

\section{Introduction}

Carbonyl sulfide (COS) is a long-lived gas in the atmosphere with an atmospheric lifetime of approximately 2-3 years (Griffith et al., 1998). Early reports suggested that COS was the principal source of sulfate particles in the stratosphere (Crutzen, 1976) with an important impact on the stratospheric ozone cycle and the Earth's radiation budget. More recent investigations have shown that shorter-lived sulfur species can be transported from near the Earth's surface into the stratosphere through convective activity, so the role of COS on the chemistry and radiation budget of the stratosphere is still open to some debate (e.g. Kjellström, 1998; Rodhe, 1999). The cycle of COS through the atmosphere, oceans, and biosphere has not been totally elucidated, and the seasonal cycle of its sources and sinks is just beginning to be understood. The COS cycle shows some similarities with $\mathrm{CO}_{2}$ (which has been the subject of many more investigations) and insight into the atmospheric cycle of both of these species will lead to further understanding of other long-lived compounds.

Until recently, the COS budget has been analyzed through literature reviews and data syntheses. Global extrapolations were made of the available information to assess the dominant production and destruction mechanisms of COS and its precursors to the atmosphere. Chin and Davis (1993) created an annual averaged budget for $\mathrm{COS}$ and $\mathrm{CS}_{2}$, and this was subsequently updated by Watts (2000) incorporating information that oxic soils take up COS instead of producing it. Kettle et al. (2002) built on this work and proposed a seasonal and spatial variation in the fluxes associated with the time dependent amplitude modulation of the major sources and sinks. None of the database estimates of the fluxes is constrained by existing databases of COS mixing ratios. Applying a global circulation model, Kjellström (1998) pointed out significant discrepancies between the databases for the

(C) European Geosciences Union 2002 

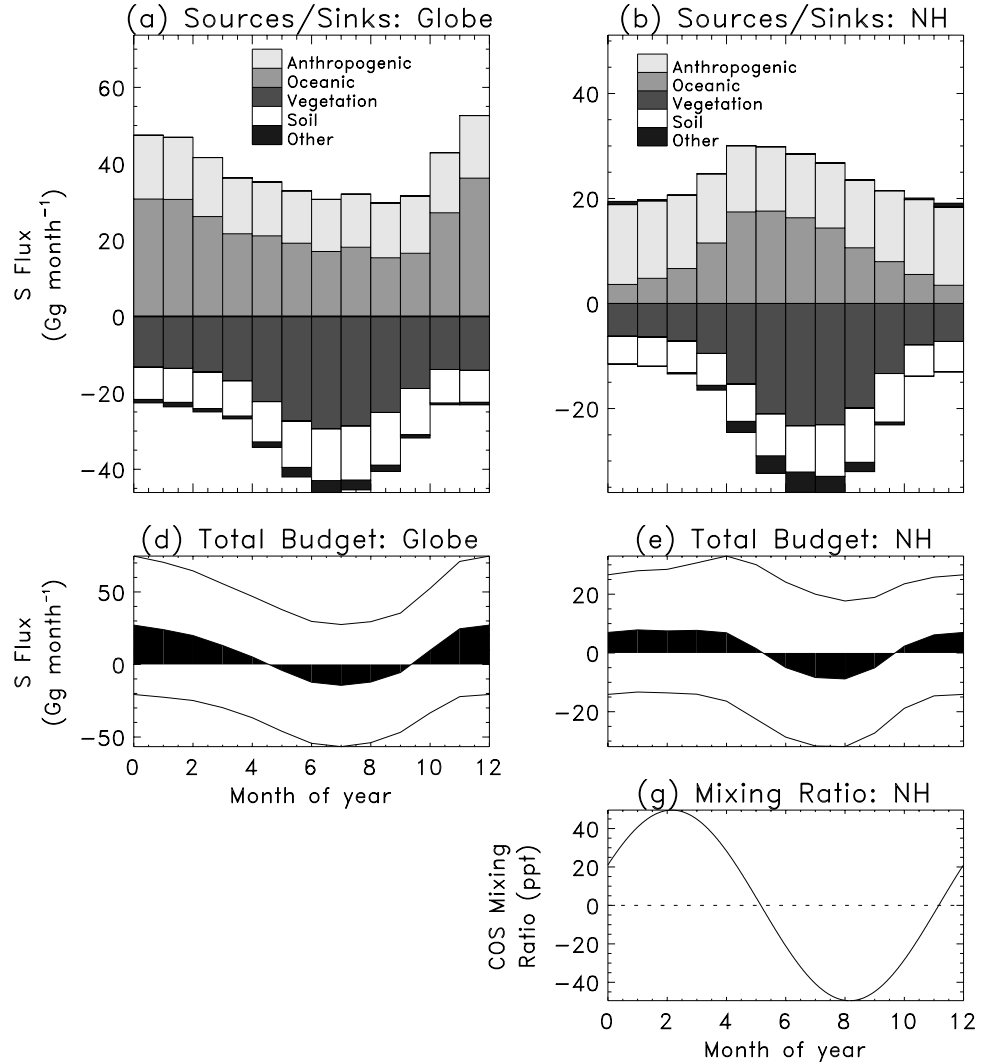

(b) Sources/Sinks: NH

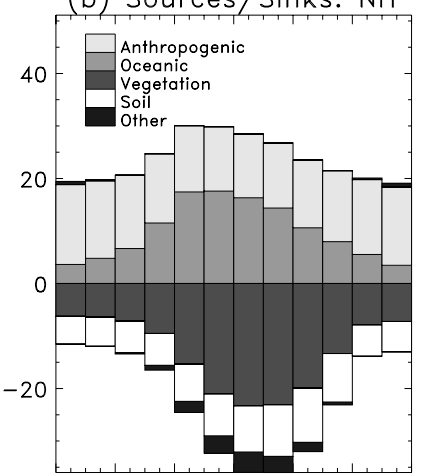

(e) Total Budget: $\mathrm{NH}$

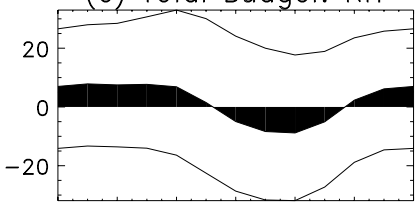

(g) Mixing Ratio: $\mathrm{NH}$
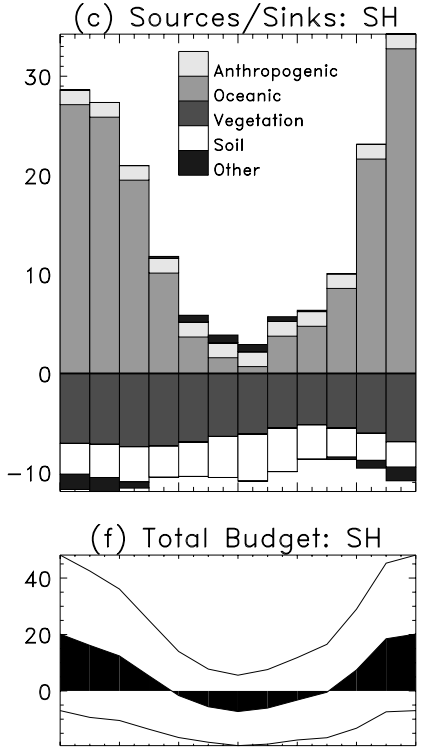

(h) Mixing Ratio: $\mathrm{SH}$

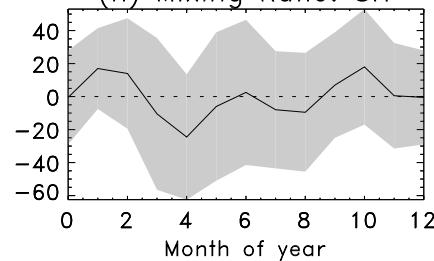

Fig. 1. Summary of the seasonal hemisphere and global integrated COS fluxes from Kettle et al. (2002) and seasonal COS atmospheric mixing ratios from two long-term time series. Itemized budgets of the major sources and sinks are shown for the (a) globe, (b) Northern Hemisphere, and (c) Southern Hemisphere. Monthly sums of the sources and sinks are shown for the (d) globe, (e) Northern Hemisphere, and (f) Southern Hemisphere. (Best guess estimates shown by the shaded region and the uncertainty is given by the upper and lower lines). The seasonal COS mixing ratio (with the average value subtracted) for the Taunus Observatory near Frankfurt, Germany is shown by a fitted equation from $\mathrm{Xu}$ (2000) in (g). The COS mixing ratio (with the average value subtracted) for a one year observation period from Amsterdam Island, Indian Ocean (Mihalopoulos, 1989) is shown in (h) with shading used to denote the standard deviation of the individual measurements for a given month.

sources and sinks and known COS atmospheric mixing ratios. Specifically, the model made predictions of the interhemispheric ratio of COS atmospheric concentrations that were opposite to what has actually been observed. These results highlighted the limitations of the existing databases and/or of the forward modeling approach.

A different modeling technique is to use a network of COS atmospheric concentrations to derive the magnitude of the COS sources and sinks using an inverse approach. The amount of data required to calculate fluxes using an inverse technique depends on the temporal and spatial resolution desired for the flux estimate, the uncertainty in the data, and the skill of the model used to describe the geophysical system (e.g. Plumb and Zheng, 1996). Even a sparse data set can be used to constrain a simplified hemisphere-box model of the Earth's atmosphere and thus achieve broad estimates of integrated sources and sinks. In this paper we explore COS sources and sinks with such a box model and compare the re- sults with the forward model compiled by Kettle et al. (2002). In particular, we wanted to assess whether the seasonal variation in the magnitude of the COS atmospheric loading was consistent with observations of total column COS made at different stations in both the Northern and Southern Hemispheres. Furthermore, we were interested in addressing the question raised by Kettle et al. (2002) about the relative importance of the Northern Hemisphere COS sink associated with plant and soil uptake during boreal summer, compared with the ocean uptake during boreal winter.

\section{Methods}

\subsection{Summary of COS fluxes based on databases}

Estimates of seasonal COS fluxes from the oceans and anthropogenic activities and uptake by land plants and soils are shown in Fig. 1. This is a summary of the work of Kettle et 

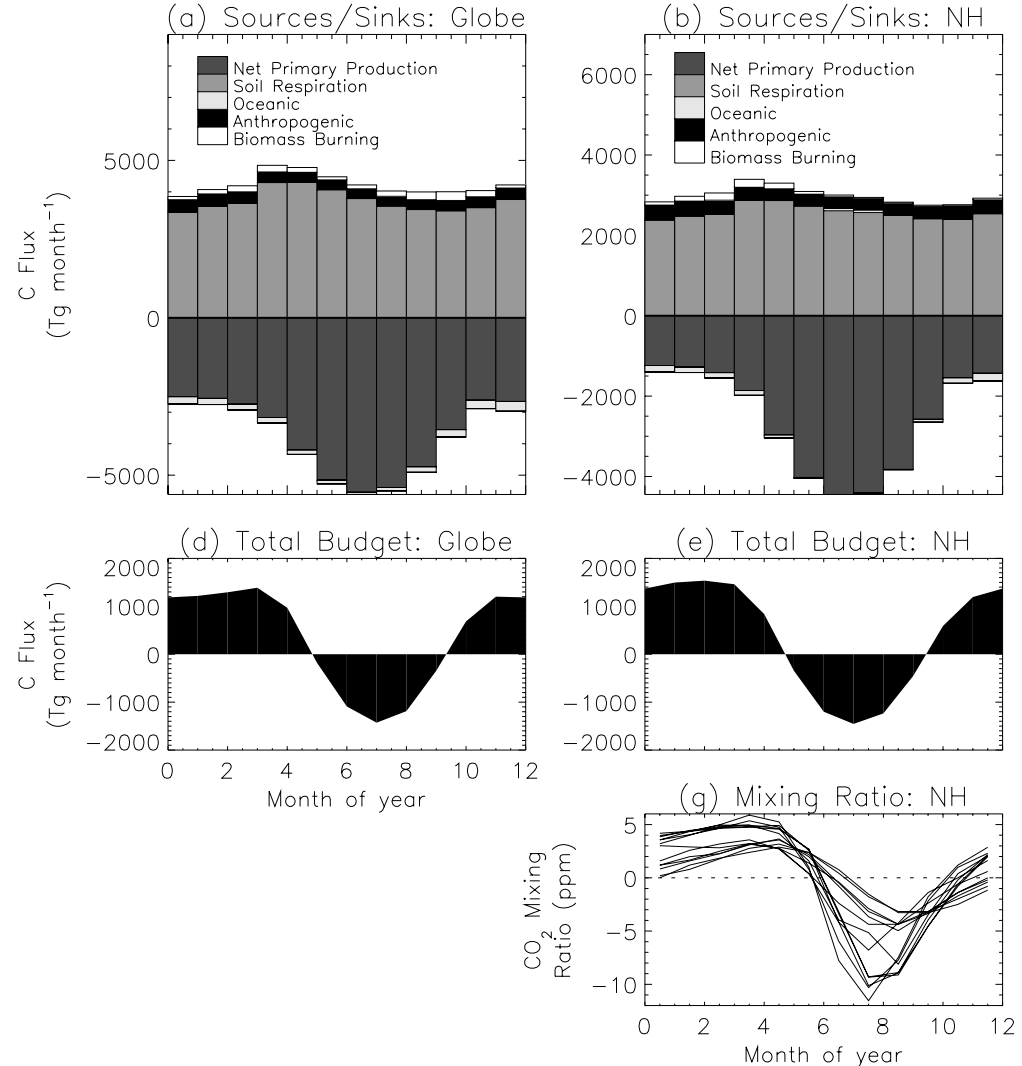
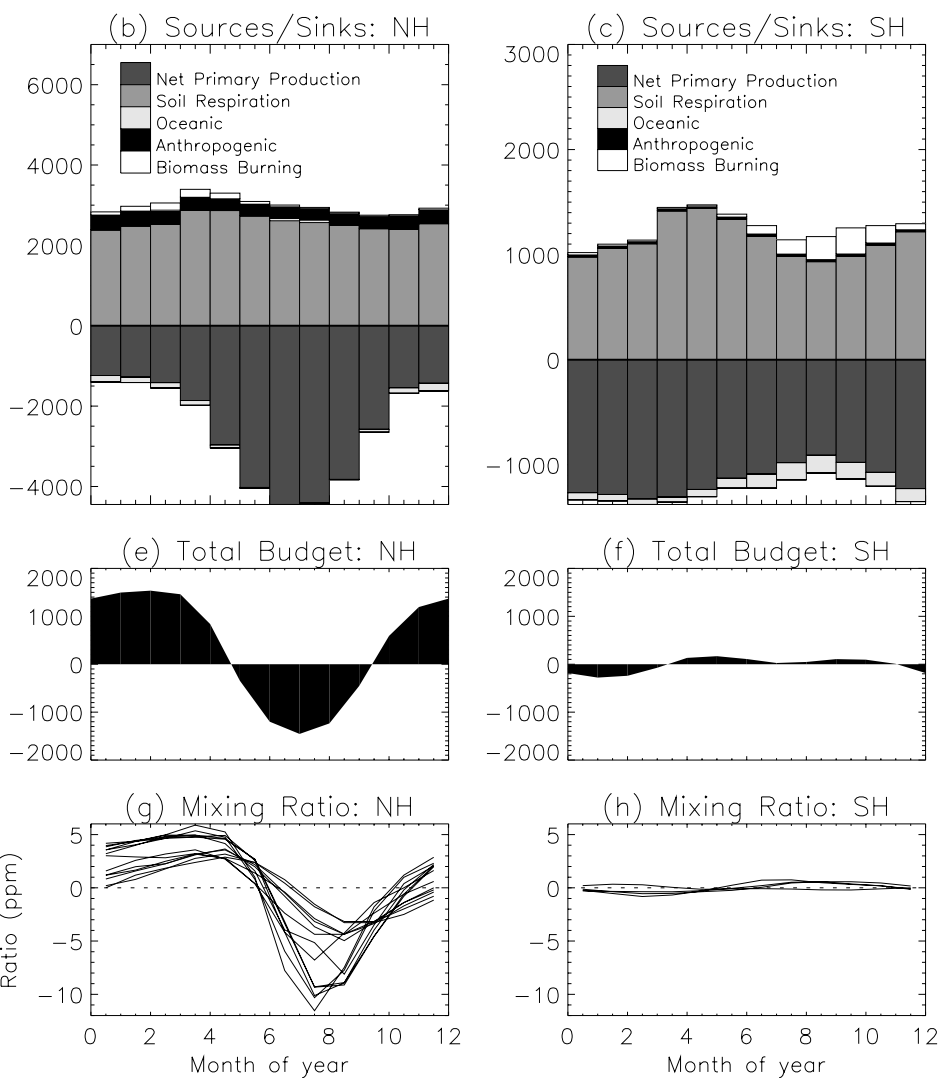

Fig. 2. Summary of the approximate seasonal hemisphere and global integrated $\mathrm{CO}_{2}$ flux from published sources and seasonal $\mathrm{CO}_{2}$ atmospheric mixing ratios from several long-term time series stations. Itemized budgets of the major sources and sinks are shown for the (a) globe, (b) Northern Hemisphere, and (c) Southern Hemisphere. Monthly sums of the sources and sinks are shown for the (d) globe, (e) Northern Hemisphere, and (f) Southern Hemisphere. The seasonal average $\mathrm{CO}_{2}$ mixing ratios (with the average value subtracted) for long-term $\mathrm{CO}_{2}$ monitoring stations have been digitized from Randerson et al. (1997) and are shown for the (g) Northern and (h) Southern Hemispheres.

al. (2002) and represents a priori knowledge against which inverse model flux calculations will be compared later. For the Northern Hemisphere (Fig. 1b), the main COS sources are anthropogenic activities and ocean outgassing, and the main sinks are thought to be uptake by land plants and soils. The seasonal variation in the flux is due mainly to the relative strength of the oceanic input and destruction by vegetation. The sum of all the sources and sinks (Fig. 1e) indicates that there is a net COS input to the Northern Hemisphere atmosphere in boreal winter and a net removal from the atmosphere in boreal summer. (There is significant uncertainty associated with many of the individual source and sink terms in Fig. $1 \mathrm{~b}$ and also with the net sum in Fig. 1e, and this is discussed in detail in Kettle et al., 2002). The seasonal cycle in the Northern Hemisphere flux is consistent with mixing ratios from the one known long-term Northern Hemisphere monitoring station near Frankfurt, Germany (Xu, 2000), with high values in February and low values in August (a fitted curve is shown Fig. 1g).

In the Southern Hemisphere, the main source of COS to the atmosphere is outgassing from the oceans and the main sinks are uptake by land plants and soils (Fig. 1c). The sum of the all the sources and sinks in the Southern Hemisphere (Fig. 1f) shows a net COS source to the atmosphere in austral summer and net COS removal from the atmosphere in austral winter (also with the large uncertainty range noted for the Northern Hemisphere budget). Mixing ratio data from one station at Amsterdam Island in the Indian Ocean (Mihalopoulos, 1989) (Fig. 1h) show a complicated seasonal cycle with elevated mixing ratios in October-February and also, unexpectedly, in June-July, when the hemisphereintegrated flux shows a minimum value. The amplitude of these monthly variations is smaller than the standard deviation of the individual measurements, and it is difficult to recognize a clear seasonal cycle in this data (Mihalopoulos et al., 1991). However, the apparent discrepancies between the seasonal cycle of the mixing ratios at Amsterdam Island and the hemisphere-integrated COS fluxes may be resolved by considering the effects of atmospheric transport and the seasonal variation of biomass burning patterns in southern Africa. Specifically, the work of Dentener et al. (1999) on the short-lived radionuclide $\mathrm{Rn}^{222}$ (a tracer of continental air 
Northern Hemisphere

Southern Hemisphere

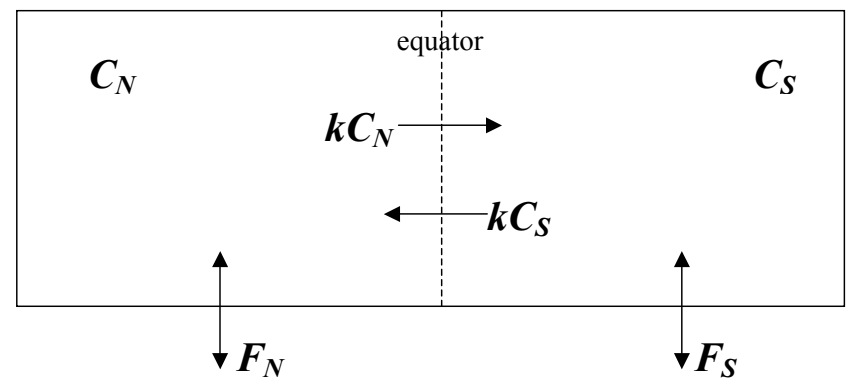

Fig. 3. Schematic diagram of the box model used to simulate COS loading in the Northern and Southern Hemispheres. $C_{N}$ and $C_{S}$ are the COS hemisphere-integrated loading for the Northern and Southern Hemisphere, $k$ is the interhemispheric exchange time, $k C_{N}$ and $k C_{S}$ are the COS fluxes across the equator from the Northern and Southern Hemispheres, and $F_{N}$ and $F_{S}$ are the biogeochemical source and sink terms in the Northern and Southern Hemispheres (including surface fluxes and volume source and sink terms).

pollution) indicates that there is enhanced transport between southern Africa and Amsterdam Island in July and August. These are months of maximum biomass burning in southern Africa that have been identified by Marufu et al. (2000), and there is a strong possibility that the peak COS mixing ratios observed at Amsterdam Island in July and August may be due to COS originating from biomass burning in Africa.

In some respects, the behavior of COS in the atmosphere is similar to $\mathrm{CO}_{2}$, another long-lived atmospheric tracer, which has been studied more-comprehensively. The global and hemisphere-integrated fluxes of $\mathrm{CO}_{2}$ have been formulated in the same manner as for COS (outlined in the Appendix) and are shown in Fig. 2. For both the Northern and Southern Hemispheres, the budget shows a dominant balance between the soil respiration source and net primary production sink on land areas (Fig. 2a-c). (There is also a large $\mathrm{CO}_{2}$ flux both into and out of the oceans, but the hemisphere-integrated net fluxes, which were calculated from the fields of Wanninkhof et al. (2001) and Takahashi et al. (2002), are small). A large seasonal variation in $\mathrm{CO}_{2}$ flux is anticipated in the Northern Hemisphere (Fig. 2e), associated with the different temporal trends in the sources and sinks. The same magnitude of variation in $\mathrm{CO}_{2}$ flux is not predicted in the Southern Hemisphere mainly because a larger fraction of the net primary production and cell respiration takes place in tropical regions, which does not vary as much seasonally as the mid and high latitudes. The seasonal variation of the detrended mixing ratios from stations in the Northern (Fig. 2g) and Southern (Fig. 2h) Hemispheres (information digitized from Randerson et al., 1997) shows good correspondence in phase and magnitude to the predicted fluxes. Interestingly, the seasonal trend and amplitude of the mixing ratios at most of the stations in the Northern Hemisphere resemble each other especially at the higher latitudes, and the same is also true for the few stations in the Southern Hemisphere. This supports the assumption that the atmosphere can be modeled as a two-box system to describe the general behavior of long-lived chemical tracers.

A comparison of the sources and sinks of $\mathrm{COS}$ and $\mathrm{CO}_{2}$ in Fig. 1 and 2 shows that the dominant sink for both species is uptake by vegetation, but there are other sources and sinks that do not behave similarly. COS is introduced to the atmosphere mainly from the oceans and anthropogenic sources whereas $\mathrm{CO}_{2}$ is introduced mainly through soil respiration and anthropogenic/biomass burning activities. Soils have been identified as a major sink of COS from the atmosphere, but they are the most important source of atmospheric $\mathrm{CO}_{2}$ over an annual cycle. The chemical differences result from the fact that COS is thermodynamically unstable in the atmosphere with respect to $\mathrm{CO}_{2}$ and oxidizes in the presence of water or catalytic surfaces (Rhodes et al., 2000). $\mathrm{CO}_{2}$, by contrast, is already in its most stable oxidation state and must be removed by a photosynthesis reduction process or dissolution in seawater. The differences in chemical behavior are reflected in the chemical lifetimes (i.e. global atmospheric loading divided by the sum of the annual removal rates from Fig. 1 and 2), which are calculated from the databases to be about 3.5 and 13.3 years for atmospheric $\mathrm{COS}$ and $\mathrm{CO}_{2}$, respectively.

\subsection{Box model description}

The COS loading of the atmosphere is described in terms of a box model in which the COS atmospheric loading of the Northern and Southern Hemispheres is parameterized as two well-mixed reservoirs with surface fluxes and atmospheric chemical processes comprising inputs and outputs (shown in Fig. 3). Keeling (1973) described the use of this kind of box model in the description of chemical fluxes among reservoirs in the Earth system, and Ulshöfer and Andreae (1998) used a simplified box model to investigate the influence of anthropogenic fluxes on atmospheric COS mixing ratios. The COS box model used in the present investigation is similar to that formulated by Newell et al. (1974) to explain the interhemispheric characteristics of $\mathrm{CO}$ atmospheric mixing ratios in early studies. These kinds of box models have in many cases been superseded by global circulation models, which have enabled the identification of the spatial distribution of source and sink regions for many chemical species whose mixing ratios have been measured with high spatial and temporal density. Global circulation models have proven useful in the identification of the source and sink regions of $\mathrm{CO}_{2}$, particularly when combined with an inverse approach (e.g. Bousquet et al., 1999). However, hemispheric box parameterizations still provide a useful check on the output of the more sophisticated global circulation models (e.g. Tans et al., 1990; Law et al., 1996). Box models are especially useful in the investigation of the hemispheric atmosphere loading of chemical tracers where a limited number of time series 
measurements are available to constrain source and sink estimates.

The processes which govern the amount of COS in each hemisphere $\left(C_{N}\right.$ or $\left.C_{S}\right)$ are the biogeochemical source and sink terms in each hemisphere $\left(F_{N}\right.$ or $\left.F_{S}\right)$, the exchange of mass between the hemispheres (defined as a first order process with an interhemispheric exchange time constant $(k)$ with a value of 1 year $^{-1}$; Law et al., 1996), and physical transport processes $(T)$ that may influence the distribution of the atmospheric mass between the two hemispheres. The budget of COS in each hemisphere is described by the following mass conservation equations:

$$
\begin{aligned}
& \frac{\mathrm{d} C_{N}}{\mathrm{~d} t}=-k C_{N}+k C_{S}+F_{N}+T \\
& \frac{\mathrm{d} C_{S}}{\mathrm{~d} t}=-k C_{S}+k C_{N}+F_{S}-T
\end{aligned}
$$

The flux of COS from one hemisphere to the other is parameterized as a first order process that is dependent on the mixing ratio in the originating hemisphere. All processes within a given hemisphere are assumed to be time-dependent terms whose annual integrated sum is equal to zero (imposing a condition that there is no interannual increase or decrease of COS within either hemisphere), but whose instantaneous sum is not necessarily zero (creating the possibility of seasonal variations of global-integrated COS loading). The assumption that there is no secular trend in the global integrated fluxes is supported by the extended total column COS measurements of Rinsland et al. (1992) and Griffith et al. (1998) and by the firn air COS mixing ratio measurements of Sturges et al. (2001). To a first approximation, the sources and sinks are assumed not to depend on the mixing ratio within the hemisphere, and this seems valid given that the observed mixing ratios are constant to within about $10 \%$.

The transport term $T$ was introduced to account for the possibility of large-scale transport of atmospheric mass between the hemispheres as part of a type of annual atmospheric tide. It reflects the suggestion of Rinsland et al. (1992) and Griffith et al. (1998) that a large part of the observed annual variation in total column COS is due to the annual cycle in the height of the tropopause, with an associated vertical movement in the a priori COS mixing ratio profiles (with a smaller part being due to seasonal variation in the surface fluxes). However, a review of the literature has revealed that the apparent vertical seasonal motion of the a priori COS mixing ratio profiles is due to chemical processes in the troposphere and stratosphere and not to physical transport processes. The height of the tropopause is defined according to vertical temperature gradient criteria (e.g. Seinfeld and Pandis, 1998). Its seasonal variation is due to changes in the temperature structure of the atmosphere associated with the local radiation budget, rather than large-scale subsidence motions associated with mass convergence or divergence within the troposphere. Thuburn and Craig (1997,
2000) have investigated how the seasonal variation of the vertical temperature gradient (and the height of the tropopause) is related to the seasonal variation in surface temperatures with its associated impact on the vertical distribution of water vapor in the troposphere.

Therefore, the annual variation in the height of the tropopause identified by Rinsland et al. (1992) and Griffith et al. (1998) is based on a redistribution of heat in the upper troposphere and not necessarily linked to a seasonal variation in the vertical COS mixing ratio profile. The seasonal variation in total column COS that is due to a tidal-type of physical transport of atmospheric mass between the hemispheres is probably very small, if total column ozone is taken as a proxy (Logan, 1999). Similarly, the diurnal variation in atmospheric mass (and also total column COS) over any given point on the Earth's surface is probably only on the order of about $0.5 \%$ as indicated by diurnal variations of sea level pressure (e.g. Kettle, 2000). The COS transport term $T$ is therefore not a first order effect in comparison to the known sources and sinks, but it is retained in this model parameterization for completeness.

The shape of the vertical COS mixing ratio profile may change if tropospheric COS is subjected to a change in chemical sink processes (e.g. photolysis and reaction with the $\mathrm{O}$ and $\mathrm{OH}$ radicals) on being sequestered in the stratosphere during a descent of the tropopause during winter conditions. Therefore, the seasonal variation in total column COS, which Rinsland et al. (1992) and Griffith et al. (1998) ascribe to changes in tropopause height, is instead to be categorized as a variation in the chemical sink strength in the database compilations of Chin and Davis (1993), Watts (2000), and Kettle et al. (2002).

The solution to the system of Eqs. (1) and (2) is developed as the sum of a steady-state component and a timedependent component for concentration, interhemispheric flux, and transport processes:

$$
\begin{aligned}
& C_{x}=\bar{C}_{x}+C_{x}^{\prime} \\
& F_{x}=\bar{F}_{x}+F_{x}^{\prime} \\
& T=T^{\prime}
\end{aligned}
$$

where $x$ denotes either the Northern $(\mathrm{N})$ or Southern Hemispheres $(\mathrm{S})$, the overbar denotes the steady state component (i.e. the solution integrated over a one year period), and ' denotes the instantaneous or time-dependent component of the solution. The transport $(T)$ is assumed to consist only of a time-dependent term. The conservation equations then become:

$$
\begin{aligned}
& \frac{\mathrm{d}\left(\overline{C_{N}}+C_{N}^{\prime}\right)}{\mathrm{d} t}=-k\left(\overline{C_{N}}+C_{N}^{\prime}\right) \\
& +k\left(\overline{C_{S}}+C_{S}^{\prime}\right)+\left(\overline{F_{N}}+F_{N}^{\prime}\right)+T^{\prime}
\end{aligned}
$$




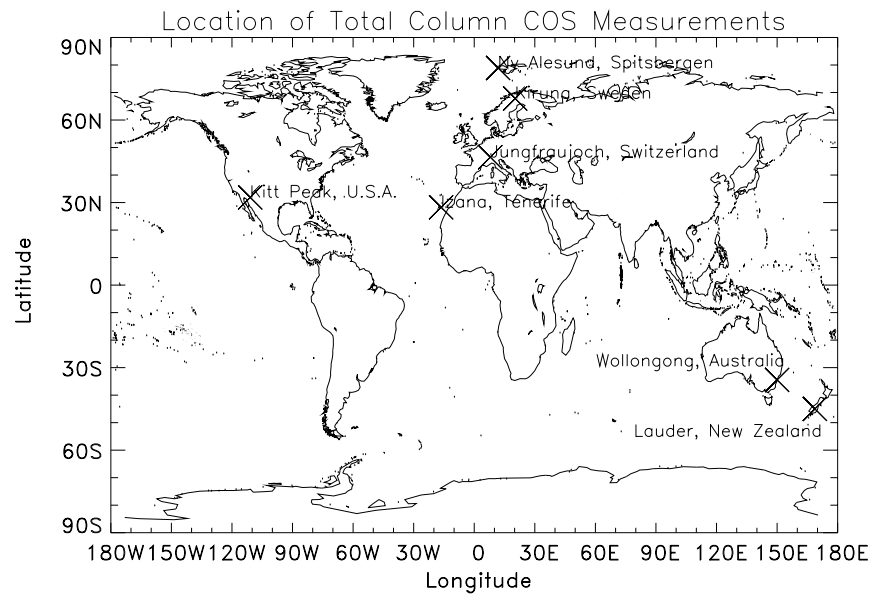

Fig. 4. Location of stations where time series measurements of total column COS measurements have been made.

$$
\begin{aligned}
& \frac{\mathrm{d}\left(\overline{C_{S}}+C_{S}^{\prime}\right)}{\mathrm{d} t}=-k\left(\overline{C_{S}}+C_{S}^{\prime}\right) \\
& \quad+k\left(\overline{C_{N}}+C_{N}^{\prime}\right)+\left(\overline{F_{S}}+F_{S}^{\prime}\right)-T^{\prime}
\end{aligned}
$$

The steady-state solution is obtained by integrating the conservation equations over a one-year period. The time derivatives of the steady-state quantities are zero, and the time dependent components $\left(C_{x}^{\prime}, F_{x}^{\prime}\right.$, and $\left.T^{\prime}\right)$ are cyclic in nature so that their annual-integrated values are zero. The steady-state parts of the conservation equations may be isolated and rewritten to obtain the following expressions for the steady-state hemisphere-integrated fluxes:

$\overline{F_{N}}=k\left(\overline{C_{N}}-\overline{C_{S}}\right)$

$\overline{F_{S}}=k\left(\overline{C_{N}}-\overline{C_{S}}\right)$

Subtracting these equations gives the net flux between hemispheres:

$\overline{F_{N}}-\overline{F_{S}}=2 k\left(\overline{C_{N}}-\overline{C_{S}}\right)$

In the steady-state (or annual-integrated) case, this equation shows that there will be a steady flux of COS from the hemisphere with the higher average COS mixing ratio to the hemisphere with the lower average COS mixing ratio. To maintain a higher steady-state COS loading in the source hemisphere compared with the sink hemisphere, as much COS must be produced (net) in the source hemisphere as is being destroyed (net) in the sink hemisphere.

Subtracting Eq. (8) from Eq. (6) and Eq. (9) from Eq. (7) gives the time-dependent part of the conservation equations:

$\frac{\mathrm{d} C_{N}^{\prime}}{\mathrm{d} t}=-k C_{N}^{\prime}+k C_{S}^{\prime}+F_{N}^{\prime}+T^{\prime}$ $\frac{\mathrm{d} C_{S}^{\prime}}{\mathrm{d} t}=-k C_{S}^{\prime}+k C_{N}^{\prime}+F_{S}^{\prime}-T^{\prime}$

Adding these conservation equations together gives:

$\frac{\mathrm{d} C_{N}^{\prime}}{\mathrm{d} t}+\frac{\mathrm{d} C_{S}^{\prime}}{\mathrm{d} t}=F_{N}^{\prime}+F_{S}^{\prime}$

Differentiating the conservation equations (Eqs. 11 and 12) with respect to time and then rearranging and substituting Eq. (13) results in a pair of forced second order differential equations:

$\frac{\mathrm{d}^{2} C_{N}^{\prime}}{\mathrm{d} t^{2}}+2 k \frac{\mathrm{d} C_{N}^{\prime}}{\mathrm{d} t}=k F_{N}^{\prime}+k F_{S}^{\prime}+\frac{\mathrm{d} F_{N}^{\prime}}{\mathrm{d} t}+\frac{\mathrm{d} T^{\prime}}{\mathrm{d} t}$

$\frac{\mathrm{d}^{2} C_{S}^{\prime}}{\mathrm{d} t^{2}}+2 k \frac{\mathrm{d} C_{S}^{\prime}}{\mathrm{d} t}=k F_{N}^{\prime}+k F_{S}^{\prime}+\frac{\mathrm{d} F_{S}^{\prime}}{\mathrm{d} t}+\frac{\mathrm{d} T^{\prime}}{\mathrm{d} t}$

These describe the COS loading in each hemisphere in terms of the chemical sources and sinks in each hemisphere and the rate of change of the tidal term. The general solution of the forced second order differential equations has the form:

$C_{N}^{\prime}=b_{1} e^{-2 k t}+P_{N}\left(F_{N}^{\prime}, F_{S}^{\prime}, T^{\prime}\right)+b_{2}$

$C_{S}^{\prime}=b_{3} e^{-2 k t}+P_{S}\left(F_{N}^{\prime}, F_{S}^{\prime}, T^{\prime}\right)+b_{4}$

where $P_{N}$ and $P_{S}$ are particular solutions of the forced model for the Northern and Southern Hemispheres, respectively, and $b_{n}$ are integration constants of the general solution. The exact functional forms of $P_{N}$ and $P_{S}$ depend on the functional forms that are used to describe the time dependence of $F_{N}^{\prime}, F_{S}^{\prime}$, and $T^{\prime}$. The first terms on the right hand side of Eqs. (16) and (17) are the exponentially decreasing transient solutions of the homogeneous equation (derived by setting the forcing terms on the right hand side of Eqs. (14) and (15) to zero). They indicate that the atmospheric system represented by the COS box model shows no inherent ability to support resonant oscillatory solutions. Any oscillations observed in the system (e.g. from the total column COS time series of Rinsland et al., 1992 and Griffith et al., 1998 or from the COS surface mixing ratio time series of $\mathrm{Xu}, 2000$ ) are from the forcing terms in the equations.

Within this simplified description of the COS atmospheric system, the derivation of the hemispheric loading from the known fluxes is the forward approach, and the derivation of the fluxes from known atmospheric loading is the inverse approach. Problems of deriving accurate fluxes have been identified in every database compilation, and the use of these COS databases as boundary conditions to force coupled physical/chemical models leads to solutions for atmospheric COS loading with large uncertainties (e.g. Kjellström, 1998). However, there is accurate information for total column COS, and this may be used to derive relatively accurate constraints on COS fluxes. 
Table 1. Locations and times of total column COS observations

\begin{tabular}{|c|c|c|c|c|c|c|c|}
\hline Station & Latitude & Longitude & Elevation (m) & Start Date & End Date & $\mathrm{N}$ & Reference \\
\hline Kitt Peak, USA & $31.9^{\circ} \mathrm{N}$ & $111.6^{\circ} \mathrm{W}$ & 2090 & 27 May 1977 & 14 Mar 1991 & 57 & $\begin{array}{l}\text { Rinsland et al. (1992); digital } \\
\text { files from C. P. Rinsland by pri- } \\
\text { vate communication, } 2001\end{array}$ \\
\hline $\begin{array}{l}\text { Jungfraujoch, } \\
\text { Switzerland }\end{array}$ & $46.5^{\circ} \mathrm{N}$ & $8.0^{\circ} \mathrm{E}$ & 3580 & 9 June 1984 & 12 Nov 2000 & 877 & $\begin{array}{l}\text { Mahieu et al. (1997); digital } \\
\text { files from R. Zander and E. } \\
\text { Mahieu by private communica- } \\
\text { tion, } 2001\end{array}$ \\
\hline $\begin{array}{l}\text { Lauder, } \\
\text { New Zealand }\end{array}$ & $45.0^{\circ} \mathrm{S}$ & $169.7^{\circ} \mathrm{E}$ & 370 & 21 Apr 1991 & 10 May 2001 & 86 & $\begin{array}{l}\text { Griffith et al. (1998, 2001); dig- } \\
\text { ital files from D. W. T. Grif- } \\
\text { fith by private communication, } \\
2001\end{array}$ \\
\hline $\begin{array}{l}\text { Ny Ålesund, } \\
\text { Spitsbergen }\end{array}$ & $78.93^{\circ} \mathrm{N}$ & $11.88^{\circ} \mathrm{E}$ & 474 & 13 Mar 1992 & 15 July 1998 & 186 & $\begin{array}{l}\text { Notholt et al. (1997); digital } \\
\text { files from J. Notholt by private } \\
\text { communication, } 2001\end{array}$ \\
\hline $\begin{array}{l}\text { Wollongong, } \\
\text { Australia }\end{array}$ & $34.45^{\circ} \mathrm{S}$ & $150.88^{\circ} \mathrm{E}$ & 30 & 27 May 1996 & 16 Sept 2000 & 30 & $\begin{array}{l}\text { Griffith et al. (1998, 2001); dig- } \\
\text { ital files from D. W. T. Grif- } \\
\text { fith by private communication, } \\
2001\end{array}$ \\
\hline Izaña, Tenerife & $28.29^{\circ} \mathrm{N}$ & $16.49^{\circ} \mathrm{W}$ & 2385 & 5 Feb 1999 & 8 July 2001 & 181 & $\begin{array}{l}\text { Schneider (2002); digital files } \\
\text { from T. Blumenstock by private } \\
\text { communication, } 2001\end{array}$ \\
\hline
\end{tabular}

\subsection{Constraining information}

Data to constrain the 2-box model come from two main sources: measurements of COS mixing ratios of firn air recovered snow samples at high latitudes the Northern and Southern Hemispheres and a network of stations that have obtained total column COS measurements extending back several decades in some cases.

Total column COS data exist for a number of long-term baseline stations in the Northern and Southern Hemispheres as part of the Network for the Detection of Stratospheric Change (NDSC; http://www.ndsc.ncep.noaa.gov). Altogether six ground stations have been located for which total column COS data have been calculated, and these are presented in Table 1 (together with the record length) and Fig. 4. Data from a seventh station at Kiruna, Sweden are being reprocessed to obtain total column COS (T. Blumenstock, private communication, 2001). The long-term total column COS time series (from digital files provided by the measuring scientists from published sources) are shown in Fig. 5.

To justify the use of a box model to describe hemispheric COS loading, it was important to establish that the total column COS time series for a given hemisphere exhibited the same characteristics with respect to phase shift and frequency (i.e. in the same manner as the $\mathrm{CO}_{2}$ data in Fig. $2 \mathrm{~g}$ ). To assess phase shift, climatological averages for the six stations were constructed by averaging all the data for a given month over successive years (see Fig. 6). Where a particular month was not represented (indicated in the lower bar diagrams), the results from the two bracketing months with data were linearly interpolated (one month for the Kitt Peak station and five winter months for the Ny Ålesund, Spitsbergen station). The results (Fig. 6) suggest that total column COS varies according to an annual cycle for each station, and that the seasonal cycle for all the stations in a given hemisphere vary with similar phase. The Northern Hemisphere stations show a peak in the average value between May and August, and the two Southern Hemisphere stations show a peak between December and May. These phase relationships were previously noted for the stations at Kitt Peak, Jungfraujoch, Lauder, and Wollongong by Rinsland et al. (1992) and Griffith et al. (1998).

The frequency characteristics for the six COS time series were constructed using a Lomb periodogram analysis following the procedure given by Press et al. (1992). The results are shown in Fig. 7 along with levels of significance and characteristic frequency ranges for previously observed physical phenomena (as reported in Read, 1993). The results indicate that the highest peak in the frequency spectrum was at one cycle/year for almost every station. The magnitude of these peaks exceeds the 50\% significance level, below which a 


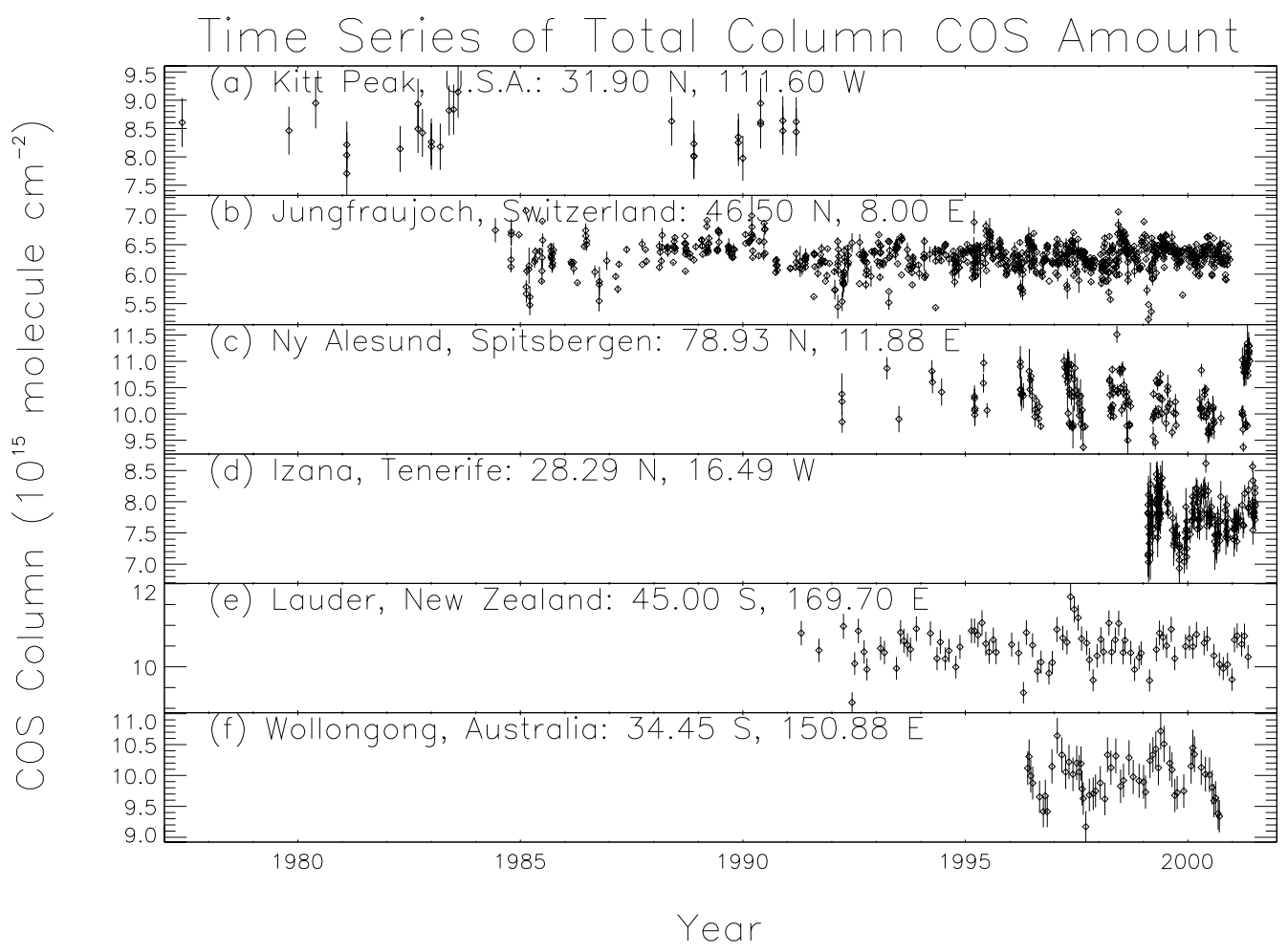

Fig. 5. Detrended time series of total column COS measurements for (a) Kitt Peak, USA (Rinsland et al. (1992); digital files from C. P. Rinsland by private communication, 2001); (b) Jungfraujoch, Switzerland (Mahieu et al. (1997); digital files from R. Zander and E. Mahieu by private communication, 2001); (c) Ny Ålesund, Spitsbergen (Notholt et al. (1997); digital files from J. Notholt by private communication, 2001); (d) Izaña, Tenerife (Schneider (2002); digital files from T. Blumenstock by private communication, 2001); (e) Lauder, New Zealand (Griffith et al. (1998, 2001); digital files from D. W. T. Griffith by private communication, 2001); and (f) Wollongong, Australia (Griffith et al. (1998, 2001); digital files from D. W. T. Griffith by private communication, 2001). The original data were detrended by fitting a straight line to the original time series, subtracting the straight line model fit from the original time series (to obtain a time series of detrended residuals), and then adding the detrended residuals to the mean of the original time series.

peak could have been attained by chance (Press et al., 1992). (The highest peak for Lauder almost touches the 50\% significance level threshold). The stations at Jungfraujoch and Ny Ålesund, Spitsbergen show two dominant peaks at one and two cycles/year. The station at Ny Ålesund, Spitsbergen shows other significant peaks at other frequencies. The most recent work of Griffith et al. (2001) has indicated that the total column COS data from the Southern Hemisphere stations are not best described with a simple cosine function, and this implies the existence of higher harmonics as observed in the periodograms. None of the peaks in the Lomb periodograms corresponds to the characteristic frequencies of quasi-periodic features that have been reviewed by Read (1993): the 'intraseasonal oscillation' of 25-60 days, 'quasibiennial oscillation' (QBO) of 20-35 months, or the El NiñoSouthern Oscillation (ENSO) of 3-6 years. Hence, the dominant signal in the total column COS time series is not interannual in nature, and the seasonal periodicity in the amplitude of total column COS signal from six different stations may be investigated using a hemispheric box model.
In addition to the total column COS measurements, the measured mixing ratios of firn air samples from glaciers on Devon Island, Canada and Antarctica (Sturges et al., 2001) provide time-averaged COS mixing ratios in the atmosphere of the Northern and Southern Hemispheres for the second half of the twentieth century. To translate the mixing ratio data into total column COS, which could be compared with the NDSC information above, it was necessary to have a priori information for the vertical profiles of atmospheric density (taken from the U.S. Standard Atmosphere, 1976) and COS mixing ratio (taken from Rinsland et al. (1992) and shown in Fig. 8 from digital files that were supplied by D. W. T. Griffith, private communication, 2002). The lowermost mixing ratios of the two profiles did not match the Northern and Southern Hemisphere mixing ratios reported by Sturges et al. (2001). Two methods were used to match the measured firn air data with the prescribed profiles: (1) scaling the prescribed profiles with a multiplicative constant to match the measured mixing ratios at the base, and (2) setting the prescribed profiles to the measured mixing ratio at the base and 

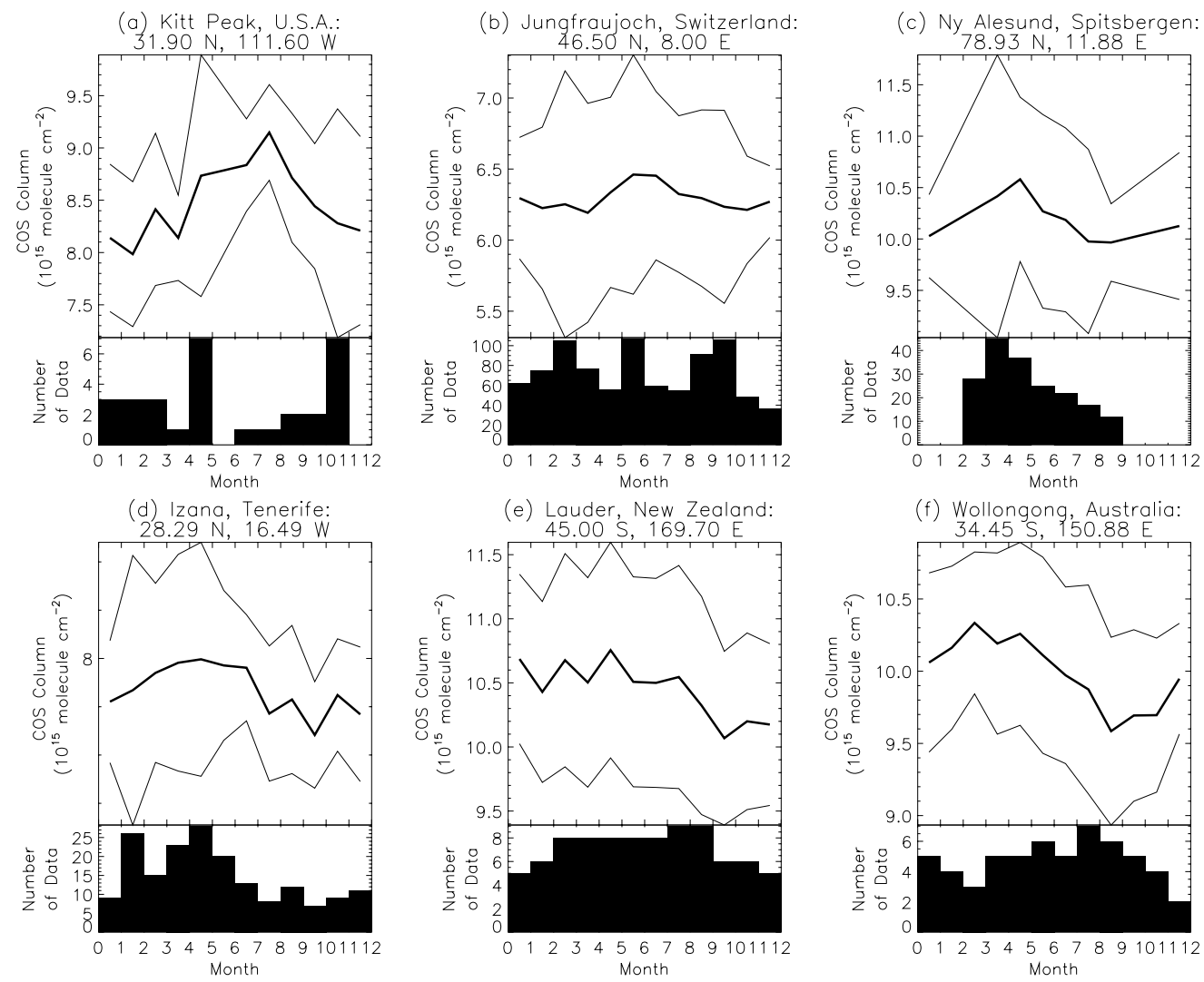

Fig. 6. Seasonal trends of total column COS measurements (with numbers of measurements within each binned month) for (a) Kitt Peak, USA; (b) Jungfraujoch, Switzerland; (c) Ny Ålesund, Spitsbergen; (d) Izaña, Tenerife; (e) Lauder, New Zealand; and (f) Wollongong, Australia. The lines show the mean \pm one standard deviation for all the data binned for a given month.

retaining the (stratospheric) mixing ratios of the prescribed profiles that are lower than the measured values at the base. These two correction methods with the two prescribed profiles resulted in four new mixing ratio profiles in each of the Northern and Southern Hemispheres (see Fig. 8) with which the total column COS and hemispheric COS loadings could be deduced from the firn air measurements.

\subsection{Model optimizations}

As part of the inverse approach, a series of optimizations have been carried out to deduce the hemisphere-integrated fluxes from observed total column COS values. The optimizations were carried out in two steps; firstly to find the steady-state part of the solution and then to deduce the timedependent perturbation of the hemisphere-integrated fluxes. All of the measurement information described in the previous section was not used in the model optimizations. Rather, selected NDSC stations were used to represent the COS loading for the Northern and Southern Hemispheres and were paired to create four scenarios: (1) Kitt Peak-Lauder, (2) Junfraujoch-Lauder, (3) Jungfraujoch-Wollongong, and (4) Kitt Peak-Wollongong (see Fig. 9). Only these four NDSC stations were chosen in this optimization analysis because they had the longest time-series records, and therefore the seasonal variations were most reliably determined. As well, all four stations were previously investigated together by Griffith et al. (1998), who presented self-consistent estimates of sea-level-adjusted total column COS amounts. The firn air mixing ratio data of Sturges et al. (2001) were also included as a fifth scenario to investigate the steady-state flux between the hemispheres.

\subsubsection{Time-dependent flux perturbation: analytical solu- tion}

The time dependent hemispheric fluxes were deduced using different approaches. An analytical solution was obtained first by using cosine functions which were fitted to the original total column COS time series by Rinsland et al. (1992) and Griffith et al. (1998):

$$
\begin{aligned}
& C_{N}=\overline{C_{N}}+A_{N} \cos \left(k_{c}\left(t-\Phi_{N}\right)\right) \\
& C_{S}=\overline{C_{S}}+A_{S} \cos \left(k_{c}\left(t-\Phi_{S}\right)\right)
\end{aligned}
$$

where $C_{x}$ denotes the time-dependent hemispheric loading based on the total column information from hemisphere $x$, 

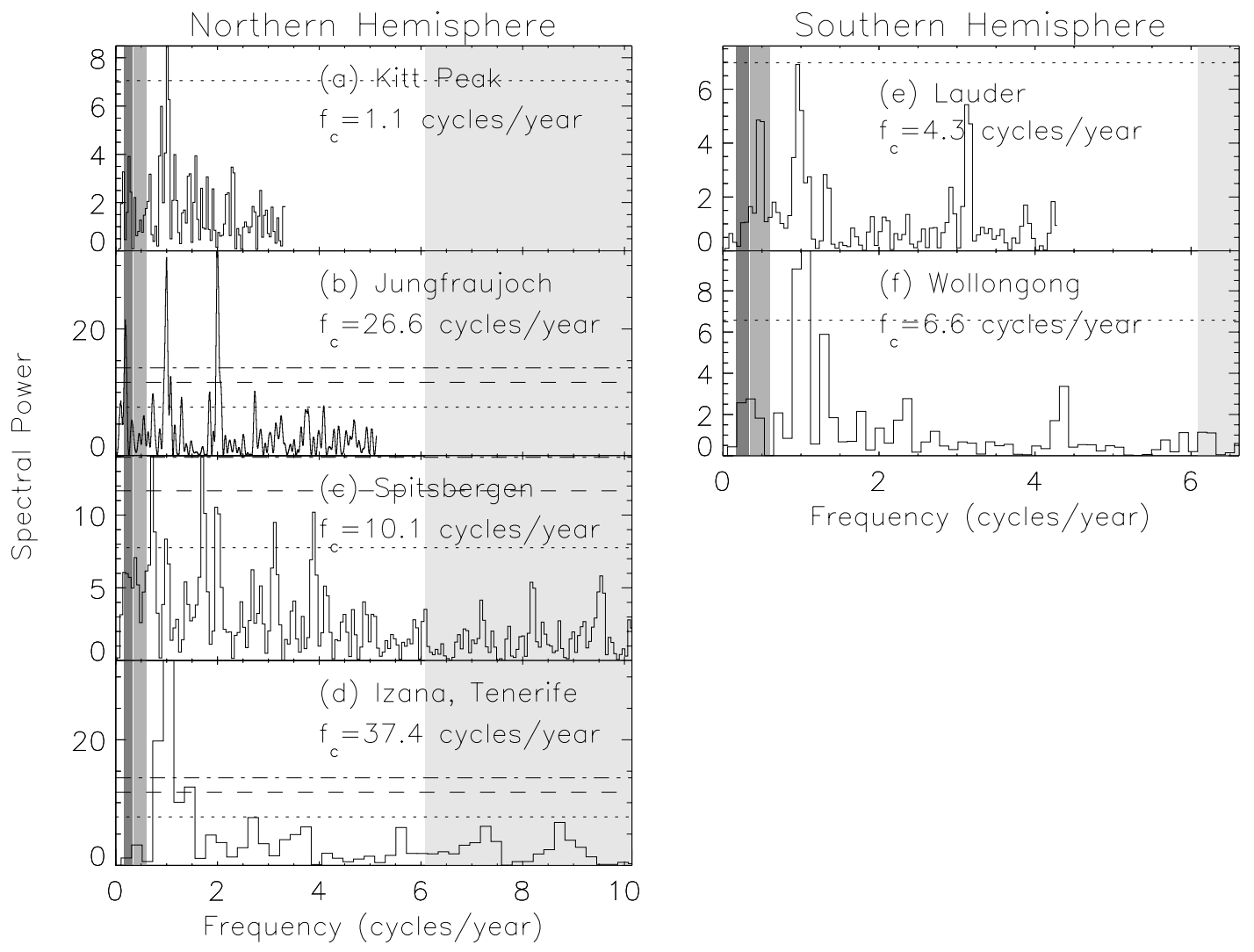

Fig. 7. Lomb periodogram frequency analysis of the detrended time series from (a) Kitt Peak, USA; (b) Jungfraujoch, Switzerland; (c) Ny Ålesund, Spitsbergen; (d) Izaña, Tenerife; (e) Lauder, New Zealand; and (f) Wollongong, Australia. Horizontal lines denote the significance of the result in terms of false-alarm probability (Press et al., 1992): dotted line, 50\%; dashed line, 10\%; and dot-dashed line, 5\%. Shading denotes frequency of quasi-periodic phenomena reported in the review by Read (1993): lightest gray shade, 'intraseasonal oscillations' of 25-60 days; middle gray shade, 'quasi-biennial oscillation' (QBO) of 20-35 months; and darkest gray shade, El Niño-Southern Oscillation (ENSO) of 3-6 years. ' $f_{c}$ ' is the one half of the reciprocal of the average time spacing for the complete data record. It would correspond to the Nyquist frequency (i.e. the highest frequency that could be resolved from the time series) for a time series where the data were equally spaced in time (Marquardt and Acuff, 1984).

$\overline{C_{x}}$ denotes the time-independent component of the hemispheric loading, $A_{x}$ is the amplitude of the sinusoidal variation of hemispheric loading, $t$ is time expressed in fractions of a year, $\Phi_{x}$ is the time of the peak COS hemispheric loading (expressed as a fraction of a year after 1 January), and $k_{c}=2 \pi$ year $^{-1}$ is a time constant. Table 2 gives the values for the constants $\overline{C_{x}}, A_{x}$, and $\Phi_{x}$ which define this parameterization. The flux in the Northern and Southern Hemispheres is calculated by substituting Eq. (18) and (19) into Eq. (1) and (2) and setting $T^{\prime}$ equal to zero:

$$
\begin{aligned}
F_{N} & =k\left(\overline{C_{N}}-\overline{C_{S}}\right)-k_{c} A_{N} \sin \left(k_{c}\left(t-\Phi_{N}\right)\right) \\
& +k A_{N} \cos \left(k_{c}\left(t-\Phi_{N}\right)\right)-k A_{S} \cos \left(k_{c}\left(t-\Phi_{S}\right)\right) \\
F_{S}= & k\left(\overline{C_{S}}-\overline{C_{N}}\right)-k_{c} A_{S} \sin \left(k_{c}\left(t-\Phi_{S}\right)\right) \\
& +k A_{S} \cos \left(k_{c}\left(t-\Phi_{S}\right)\right)-k A_{N} \cos \left(k_{c}\left(t-\Phi_{N}\right)\right)
\end{aligned}
$$

The uncertainties in the flux were evaluated analytically from the uncertainties in the constants $\overline{C_{x}}, A_{x}$, and $\Phi_{x}$ that have been presented by Rinsland et al. (1992) and Griffith et al. (1998).

\subsubsection{Time-dependent flux perturbation: simplex optimiza- tion}

Another approach was pursued that made no assumptions about the underlying functional form of the time-dependent flux. An Euler integration scheme was formulated wherein the hemispheric COS loading at the end of each successive $1 / 8$ month time step was calculated as the sum of the old hemisphere COS loading, plus the action of the flux within the given hemisphere and interhemispheric exchange during the time step. The flux at any given time was linearly interpolated from six values equally spaced through the annual cycle and centered at the beginning of months 2 (February), 4 (April), 6 (June), 8 (August), 10 (October), and 12 (December). There was a different temporal flux pattern in each 

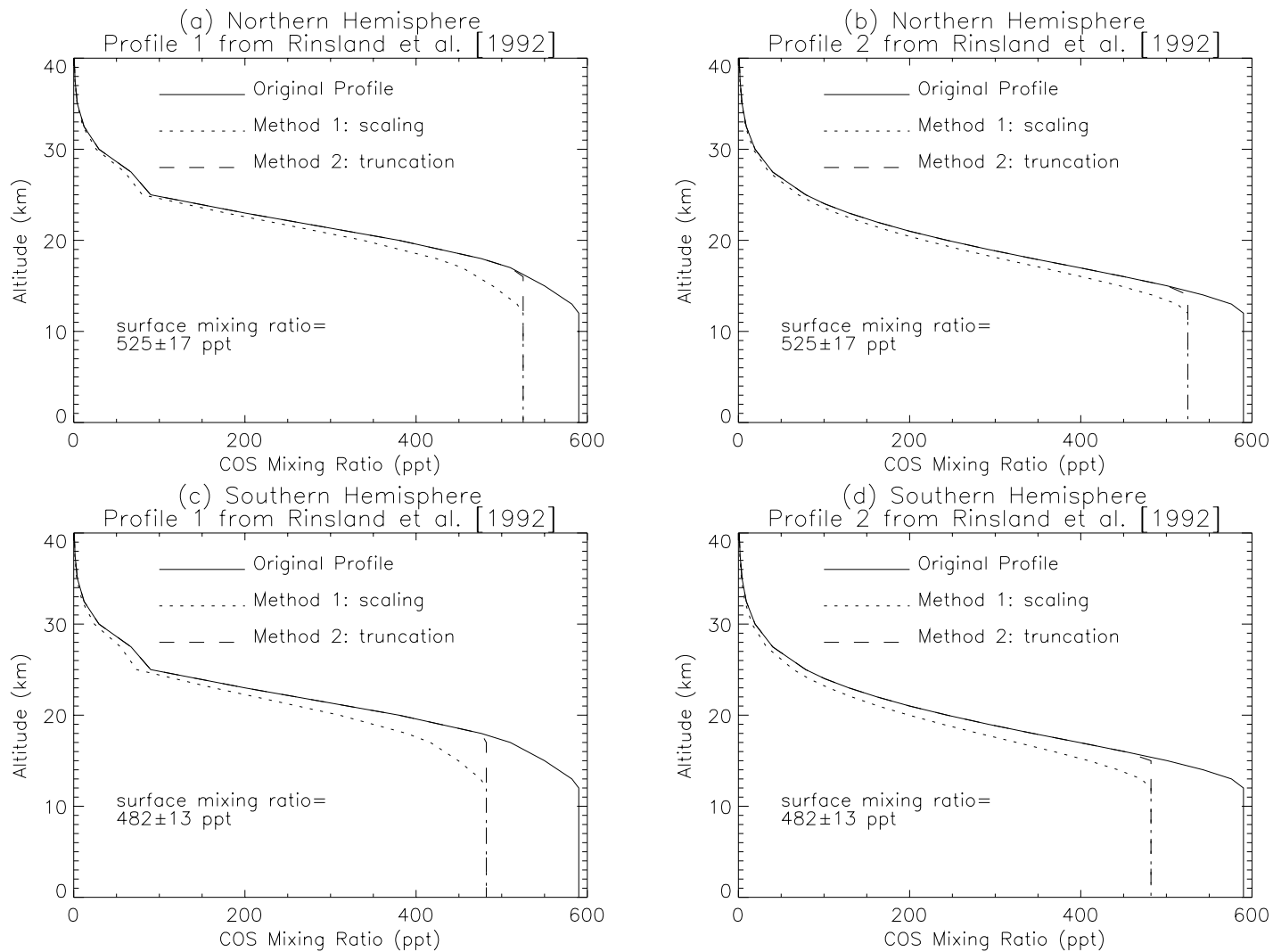

Fig. 8. Construction of COS mixing ratio profiles using firn air measurements of Sturges et al. (2001) and prescribed mixing ratio profiles 1 and 2 of Rinsland et al. (1992): (a) Northern Hemisphere using profile 1 and Devon Island firn air surface mixing ratio, (b) Northern Hemisphere using profile 2 and Devon Island firn air surface mixing ratio, (c) Southern Hemisphere using profile 1 and Antarctica firn air surface mixing ratio, and (d) Southern Hemisphere using profile 2 and Antarctica firn air surface mixing ratio. Solid lines denote the original data from Rinsland et al. (1992), dotted lines denote the modified profiles constructed from the original profiles by applying a multiplicative scaling factor, and dashed lines denote the modified profiles constructed from the original profiles by truncating mixing ratios higher than the surface firn air measurement.

Table 2. Hemispheric loading and steady-state interhemispheric flux (expressed in terms of mass of sulfur)

\begin{tabular}{|c|c|c|c|}
\hline Station & $\begin{array}{l}\text { Hemispheric COS Loading } \\
\overline{C_{x}} \text { (units of } 10^{9} \mathrm{~g} \text { of } \mathrm{S} \text { ) }\end{array}$ & $\begin{array}{l}\text { Seasonal Amplitude in } \\
\text { Hemispheric COS Loading }{ }^{2} \text {, } \\
A_{x}\left(10^{9} \mathrm{~g} \text { of } \mathrm{S}\right)\end{array}$ & $\begin{array}{l}\text { Phase Shift of Maximum in } \\
\text { Hemispheric Loading }{ }^{2} \text {, } \\
\Phi_{x} \text { (fraction of year) }\end{array}$ \\
\hline Kitt Peak, USA & $1562 \pm 15$ & $80 \pm 22$ & $0.557 \pm 0.038$ \\
\hline Jungfraujoch, Switzerland & $1453 \pm 23$ & $48 \pm 23$ & $0.592 \pm 0.074$ \\
\hline Lauder, New Zealand & $1302 \pm 6$ & $40 \pm 4$ & 0.112 \\
\hline Wollongong, Australia & $1342 \pm 5$ & $12 \pm 8$ & 0.126 \\
\hline
\end{tabular}

${ }^{1}$ hemispheric COS loading is based on the corrected total COS column above sea level presented in Griffith et al. (1998)

2 seasonal amplitude and phase shift is from Rinsland et al. (1992) for Kitt Peak and Jungfraujoch and by Griffith et al. (1998) for Lauder and Wollongong.

hemisphere so that the entire optimization problem had 12 unknown flux values equally distributed in time.

The optimized values of the 12 unknown fluxes were calculated using the downhill Simplex method (described by
Press et al., 1992 and previously used for flux estimation by Kettle, 2000). The method started with arbitrary values for the fluxes and calculated the hemispheric COS loadings at the times of the measured total column values. The root 
Northern Hemisphere

Southern Hemisphere

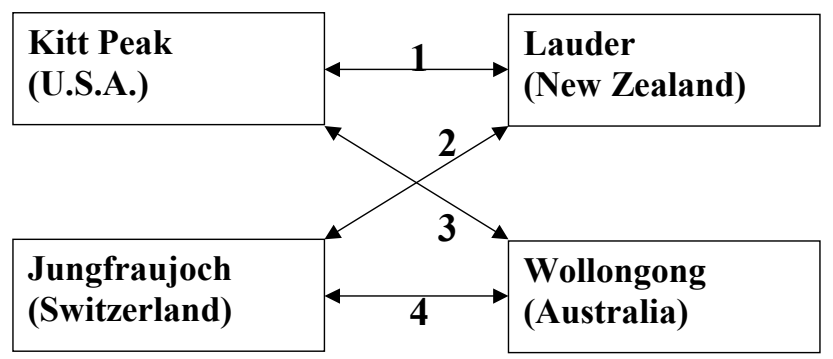

Fig. 9. Schematic diagram of the pairs of stations (scenarios) in the Northern and Southern Hemisphere that were used to calculate the optimized hemisphere-integrated fluxes.

mean square of the sum of the differences between the individual modeled and measured hemispheric loadings defined the $\chi^{2}$ value to be optimized. The optimized values for the 12 unknown fluxes represent a minimum in the $\chi^{2}$ valley in the 12 dimensional space defined by the fluxes. The Simplex method finds the minimum in the valley by assessing the impact of each of the 12 unknown values on the calculated $\chi^{2}$ value. The method then modifies the values of the 12 unknown flux values such that the new $\chi^{2}$ value is reduced. The method continues until a minimum in the $\chi^{2}$ valley is achieved. In practice, it was found that there were many local isolated minima in the $\chi^{2}$ valley because of noise in the time series and the large number of unknowns being optimized. Because of this, the final set of optimized flux values depended to some extent on the initial choice of the starting Simplex (i.e. the initial guess for the optimized values of the 12 unknown fluxes). The problem was reduced by repeating the Simplex method 25 times using different starting values of the initial Simplex. The initial starting Simplex was chosen arbitrarily, but successive trials used average values of the optimized Simplex (i.e. optimized values for the 12 unknown fluxes) that were randomly perturbed on a scale defined by the standard deviation of the optimized Simplex values. This modification assumed that there may have been a better value for the unknown fluxes than the one generated by a single Simplex optimization, and that it was in the vicinity of the existing ensemble of optimized values. The next iteration randomly chose a new starting Simplex at a nearby location. The strategy was similar to the simulated annealing procedure described by Press et al. (1992). The uncertainty associated with the starting Simplex (i.e. the uncertainty introduced by the optimization method) is mostly much smaller than the uncertainty in the estimated flux based on the Monte Carlo simulation using the uncertainty in the total column COS measurements.

The uncertainty in the optimized values of the fluxes was assessed using a Monte Carlo simulation in the same man- ner as described by Kettle (2000). This entailed generating a new data set by introducing a random Gaussian uncertainty to each of the original measurements for total column COS. The magnitude of the introduced random value was scaled according to the uncertainty of the original total column COS measurements reported in the original publications. The Monte Carlo simulation was repeated 50 times to generate enough different optimized values to calculate averages and standard deviations of the ensemble values.

\section{Results}

3.1 Steady state flux from the Northern to the Southern Hemisphere

The net steady state COS production in the Northern Hemisphere was calculated from Eq. (8) using an assumed interhemispheric exchange time of 12 months (Law et al., 1996). The Northern Hemisphere flux estimates are shown in Table 3. Each of the five scenarios considered shows a higher average COS mixing ratio in the Northern Hemisphere compared with the Southern Hemisphere (previously reported by Torres et al., 1980; Bingemer et al., 1990; Griffith et al., 1998; Sturges et al., 2001; Xu et al., 2001), indicating a steady state COS flux from the Northern to the Southern Hemisphere. The steady-state flux from the Sturges et al. (2001) data is most similar to the results based on the pairing of the total column data from Jungfraujoch and Wollongong.

3.2 Optimizations using published cosine descriptions of total column COS

Figure 10 shows the full analytical solution for the fluxes in the Northern and Southern Hemispheres for the special case where the hemispheric COS loading has been described with a cosine function. For each of the four scenarios defined in Sect. 2.4, three flux time series were calculated for the Northern and Southern Hemispheres corresponding to an interhemispheric exchange constant of 6,12 , and 24 months (i.e. the possible range in the interhemispheric exchange times noted by Law et al., 1996). The range of uncertainty for the time series calculated with an interhemispheric time constant of 12 months (i.e. the best estimate) is shown in each diagram.

The modeled flux time series using interhemispheric time constants of 12 and 24 months were closer in magnitude to the flux estimates derived from the database compilation of Kettle et al. (2002) than the flux time series using the interhemispheric time constant of only 6 months. For the Southern Hemisphere (right hand side in Fig. 10), the temporal shape, magnitude, and phase shift of the two independent flux estimates were very similar, with the maximum predicted COS input into the atmosphere in early January and the strongest removal from the atmosphere in May-June. 

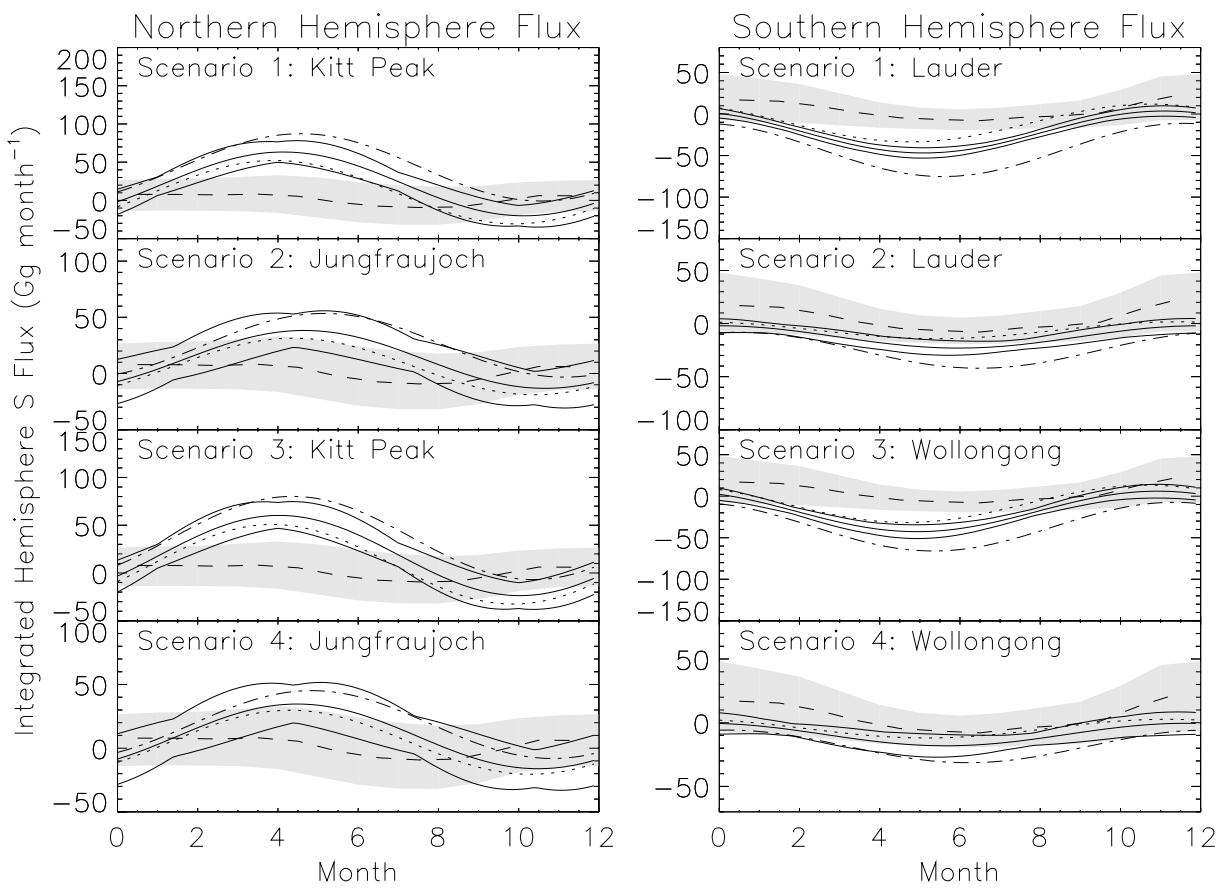

Fig. 10. Time series of estimated hemisphere-integrated COS fluxes (Northern Hemisphere: left hand side, and Southern Hemisphere: right hand side) using published cosine parameterizations for the total column COS loading and different assumed interhemispheric exchange times: dotted line, 24 months; middle solid line, 12 months; dot-dashed line, 6 months. The uncertainty in the calculated fluxes for the trial performed with an interhemispheric exchange time of 12 months is given by the upper and lower solid lines. The dashed lines and shaded regions give the best guess and estimated range of fluxes from the database investigation of Kettle et al. (2002). The COS fluxes are expressed in units of mass of sulfur per time.

Table 3. Hemispheric COS loading and steady-state interhemispheric flux (expressed in terms of mass of sulfur)

\begin{tabular}{|c|c|c|c|c|c|}
\hline Scenario & $\begin{array}{l}\text { Northern Hemisphere } \\
\text { Station }\end{array}$ & $\begin{array}{l}\text { Northern Hemisphere } \\
\text { COS Loading } \\
(109 \mathrm{~g} \text { of } \mathrm{S})\end{array}$ & $\begin{array}{l}\text { Southern Hemisphere } \\
\text { Station }\end{array}$ & $\begin{array}{l}\text { Southern Hemisphere } \\
\text { COS Loading } \\
(109 \mathrm{~g} \text { of } \mathrm{S})\end{array}$ & $\begin{array}{l}\text { Northern Hemisphere } \\
\text { COS Flux (Eq. 8), } \\
\left(10^{9} \mathrm{~g} \mathrm{month}^{-1} \text {, }\right. \\
\text { expressed as mass } \\
\text { of sulfur) }\end{array}$ \\
\hline 1 & Kitt Peak, USA & $1562 \pm 15$ & Lauder, New Zealand & $1302 \pm 6$ & $21.6 \pm 1.7$ \\
\hline 2 & Jungfraujoch, Switzerland & $1453 \pm 23$ & Lauder, New Zealand & $1302 \pm 6$ & $12.6 \pm 2.3$ \\
\hline 3 & Kitt Peak, USA & $1562 \pm 15$ & Wollongong, Australia & $1342 \pm 5$ & $18.3 \pm 1.8$ \\
\hline 4 & Jungfraujoch, Switzerland & $1453 \pm 23$ & Wollongong, Australia & $1342 \pm 5$ & $9.3 \pm 2.3$ \\
\hline Sturges et al. (2001) & Devon Island, Canada & $1450 \pm 70$ & Antarctica & $1330 \pm 50$ & $9.6 \pm 4.8$ \\
\hline
\end{tabular}

The situation is not as clear for the Northern Hemisphere flux estimate (left hand side in Fig. 10). The inverse model shows that the Northern Hemisphere flux should be described by a cosine function with a maximum COS input to the atmosphere in April or May and a maximum COS removal in December-January. The database work of Kettle et al. (2002) (dashed lines and shaded regions in Fig. 10) suggests that the temporal variations of the annual Northern Hemisphere COS flux may not best be described by a cosine function. Rather, the database work suggests that there may be an extended pe- riod of elevated COS fluxes to the Northern Hemisphere from December to March (dominated by anthropogenic emissions and perhaps by COS from DMS emissions associated with oceanic phytoplankton blooms starting in March) and a short period of COS uptake in July associated with COS uptake by soils and terrestrial plants.

Lomb periodograms of the modeled COS loading show only one significant frequency at one cycle/year (an expected result where the hemispheric COS loading has been described using a cosine function; Stull, 1988). A compar- 

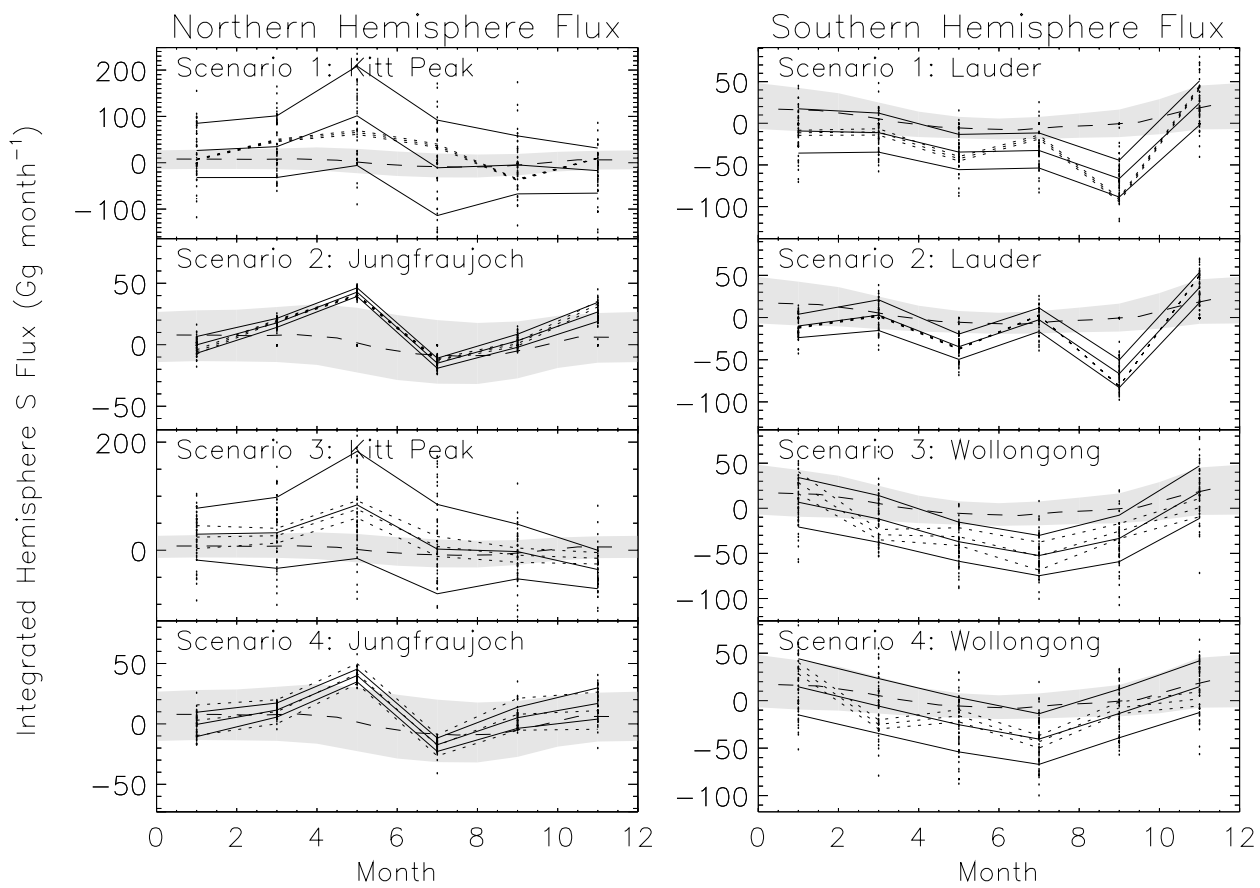

Fig. 11. Time series of estimated hemisphere-integrated COS fluxes (Northern Hemisphere: left hand side, and Southern Hemisphere: right hand side) calculated from a Simplex optimization of the detrended original COS hemispheric loadings with no assumed underlying function. The set of three dotted lines give the mean and standard deviation of 15 replicate trials where the optimized flux was derived using the measured, unperturbed hemispheric COS loadings. It is a test of the ability of the Simplex optimization method to converge on the best value of the optimized flux from different values of the starting Simplex. The vertically distributed dots give the results of 50 Monte Carlo runs wherein the optimized fluxes were determined from the measured hemispheric loadings that were perturbed by the introduction of simulated random measurement error. The solid lines give the mean and standard deviation of these 50 trials. The dashed lines and shaded regions give the best guess and estimated range of fluxes from the database investigation of Kettle et al. (2002). The COS fluxes are expressed in units of mass of sulfur per time.

ison with the corresponding Lomb periodograms of the raw data (Fig. 7) indicates that the cosine parameterization may be an effective descriptor for the seasonal evolution of the flux in the Southern Hemisphere. The best description of the seasonal evolution of the Northern Hemisphere flux is more complicated. The Lomb periodogram of the Kitt Peak and Izaña time series in Fig. 7 show only one significant peak, but the Lomb periodograms of the Jungfraujoch and Spitsbergen indicate that the signal may be made up of several frequencies and that the fitted cosine function, with only one cycle per year, may not be the best description of the time series.

3.3 Optimizations assuming no underlying functional parameterization

The COS hemispheric fluxes based on optimizations with no underlying assumptions for the functional form of the seasonal variation (Fig. 11) show different results to the previous section. The seasonal progression of the COS flux in the Southern Hemisphere (right column in Fig. 11) indicates that the largest COS flux into the Southern Hemisphere is in
December-February. The lowest COS flux is predicted to be in September-October based on the Lauder time series and July-August based on the Wollongong time series. These results agree approximately with the database estimates of Kettle et al. (2002) (shown by shading and dashed lines) in which the maximum COS flux to the Southern Hemisphere is in October-December and the minimum flux is in JuneAugust. The optimized Southern Hemisphere flux based on the Wollongong time series shows particularly good agreement with the database estimates of Kettle et al. (2002).

In the Northern Hemisphere (left hand column in Fig. 11), both the Kitt Peak and Jungfraujoch time series indicate that the largest COS flux into the atmosphere occurs in MayJune, and this corresponds to the time of maximum COS emission from the oceans as suggested by the forward model approach of Kettle et al. (2002). However, the time of lowest COS flux to the Northern Hemisphere is predicted to be November-February based on the Kitt Peak time series and July-August based on the Jungfraujoch time series. The optimized fluxes based on Kitt Peak time series show the best agreement with the database work of Kettle et al. (2002) with the highest flux into the Northern Hemisphere in the 

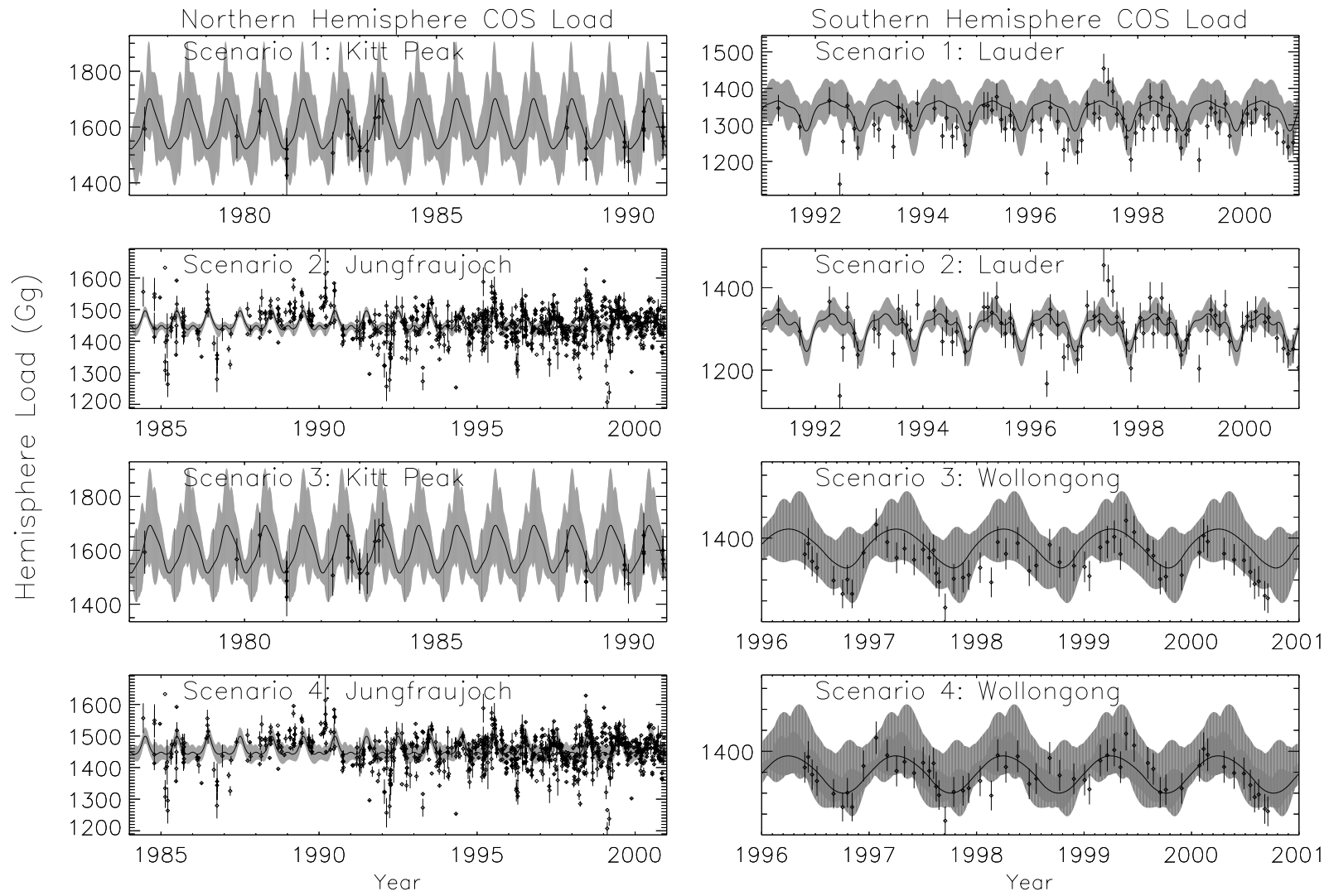

Fig. 12. Comparison of the range of predicted COS hemispheric loadings (in shading) predicted from the fluxes obtained from the 50 Monte Carlo simulations together with the hemispheric loadings derived from four sets of total column COS measurements (from Fig. 3). The solid line is the predicted hemisphere COS loading based on an average of the 50 Monte Carlo simulations. The COS loadings are expressed in terms of mass of sulfur.

January-May period and the lowest flux in the July-August period.

Kettle et al. (2002) note that it is not clear whether the seasonal cycle of COS fluxes to the Northern Hemisphere would be dominated by the oceanic source/sink term or by the land plant/soil sink terms. Specifically, the oceanic uptake of COS should be a maximum in January but that the uptake by land plants and soils should be a maximum between July-September. Because the magnitude of uptake by the different sinks could not be precisely quantified by Kettle et al. (2002), it is not certain whether the maximum COS uptake in the Northern Hemisphere would be July or January. Because a much greater density of total column COS data is available for Jungfraujoch than for Kitt Peak, scenarios 2 and 4 (where the Jungfraujoch and Southern Hemisphere time series have been paired) might be the most accurate description of the geophysical system. This suggests that the maximum COS uptake rate in the Northern Hemisphere may be July, and the COS removal from the atmosphere in the Northern Hemisphere would be dominated by plant and soil uptake in the boreal summer and not by oceanic uptake in the boreal winter.
The ensemble of hemisphere COS flux results was used to calculate a series of COS loadings for the Northern and Southern Hemispheres. The range of minimum and maximum hemisphere COS loadings from the ensemble is shown by shading in Fig. 12 along with the hemisphere loadings based on total column measurements. The COS hemisphere loading calculated from the average of the ensemble of fluxes from the Monte Carlo simulation is shown by the solid black line.

The frequency characteristics of the ensemble of 50 Monte Carlo COS hemisphere loadings are summarized in Lomb periodograms on the right hand side of Fig. 13. The Lomb periodograms show that most of the power in the seasonal variation of COS hemispheric loading is contained at a frequency of 1 cycle/year. However, there are also harmonics at 2 and 3 cycles/year that have successively lower amounts of power. Likewise, the Lomb periodograms of the raw data shown in Fig. 7 may also show evidence of higher level harmonics (particularly for the Jungfraujoch and Spitsbergen time series). This situation is unlike the scenarios wherein the COS hemispheric loading is described by a cosine function and shows only one peak in the Lomb periodogram. The 
Time Series cos Loading
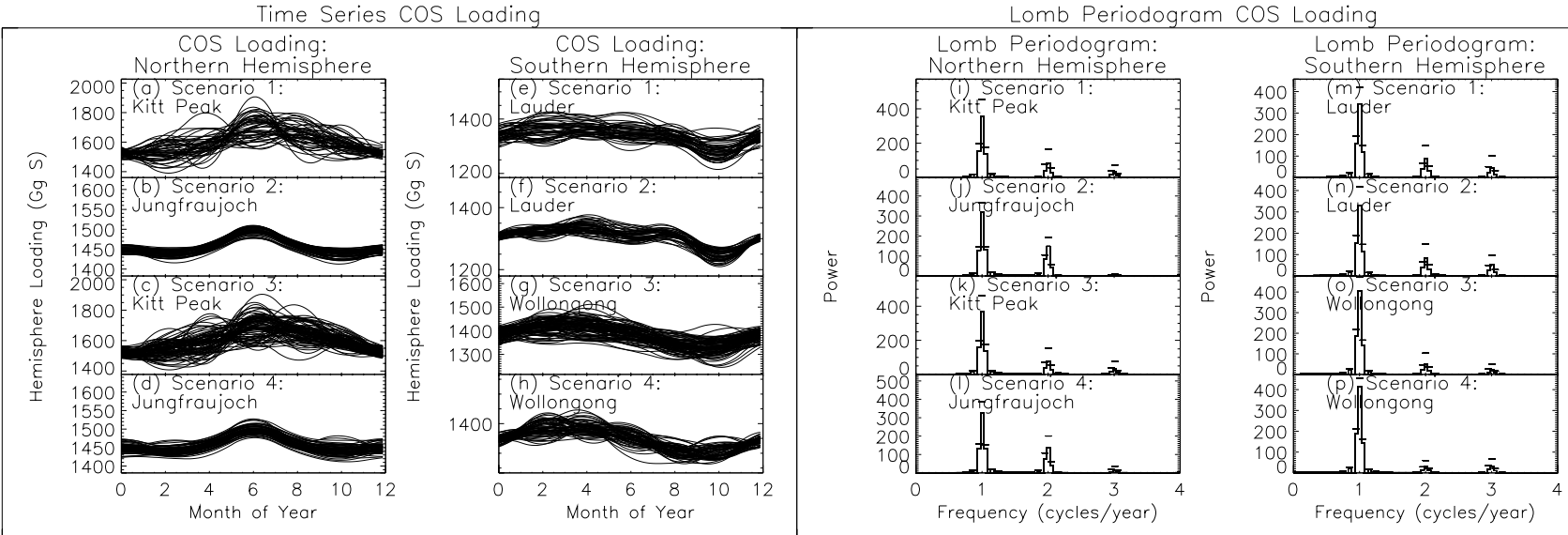

Fig. 13. Time series and Lomb periodogram frequency analysis of the COS hemispheric loading for the Northern (time series: a-d; Lomb periodograms: i-1) and Southern (time series: e-h; Lomb periodograms: $\mathrm{m}-\mathrm{p}$ ) Hemispheres from the optimized fluxes from $50 \mathrm{Monte}$ Carlo simulations. The time series on the left hand side show the results of all 50 Monte Carlo simulations. The Lomb periodograms on the right hand side show the average of the frequency analyses of the Monte Carlo results with the standard deviations denoted by short horizontal lines.

existence of higher level harmonics does not necessarily indicate a geophysical process which is acting to introduce COS to a hemisphere with a cosine functional dependence with a characteristic frequency of 2 and 3 cycles/year. More likely, the interaction of anthropogenic and natural sources and sinks combines to create a complicated periodic forcing function which has a repetition rate of 1 cycle/year, but which can be deconvolved into harmonics at higher frequencies.

\section{Conclusions}

Hemisphere-integrated COS flux optimizations based on a mathematical inversion of total column COS measurements show good agreement with database estimates formulated by Kettle et al. (2002). The optimized flux estimates are based on a two-box model of the atmosphere wherein the time series of hemisphere-integrated loading is represented by a published fitted cosine function to measured data and by a second scheme that assumes no underlying time dependent function. For the Southern Hemisphere, the seasonal, hemisphere-integrated fluxes derived from the published cosine descriptors of total column COS loading agree in phase and amplitude closely with the Kettle et al. (2002) database estimates. Not much extra information was gained from the more complicated analysis wherein fluxes were derived from the raw total column COS data. The results were somewhat different for the Northern Hemisphere. The hemisphereintegrated COS fluxes from the published cosine descriptors of the data are somewhat greater in amplitude than the database estimates of Kettle et al. (2002). On the other hand, there was good agreement in phase between the two flux estimates, and both predict a maximum COS flux into the North- ern Hemisphere in March-May; i.e. during the period associated with the spring bloom in the oceans and just before the maximum of predicted COS uptake by land plants. For the Northern Hemisphere, the optimized COS fluxes based on no underlying assumption for the functional dependence of the total column COS show better agreement in magnitude with the Kettle et al. (2002) database estimates. These Northern Hemisphere flux results also reveal that the timing of the maximum and minimum fluxes may be separated by a couple of months in the May-July period. This suggests that the seasonal variation of total column COS in the Northern Hemisphere is probably not best described with a cosine function.

The results highlight the advantages of the inverse approach as a means of global COS modeling. There is greater consistency between total column COS measurements and estimated hemisphere-integrated fluxes than is possible with a compilation of databases. This was also noted by Kjellström (1998) whose global circulation model was forced by database compilations of COS fluxes and predicted an interhemispheric ratio of atmospheric COS mixing ratios that was reversed compared to available measurements. However, the significant advantage of the global circulation model was that it was able to predict latitude, longitude, and height trends in COS mixing ratios, which is not possible with the box model used here. Future investigations could use general circulation models like the one used by Kjellström (1998) to get a better idea of the regions which are associated with the interhemispheric difference and seasonal variation of COS mixing ratios. Because at least four stations making total column COS measurements are situated around Europe, it would also be interesting to collate the measurements with HYSPLIT trajectory information in a tomographic approach 
to identify the important anthropogenic source regions on the continent. The current information for the spatial and temporal distribution of anthropogenic sources and sinks for COS in Europe was based on existing $\mathrm{SO}_{2}$ information (Kettle et al., 2002), and it would be interesting to have an independent verification of the source regions. Finally, other long-lived atmospheric chemical species (like $\mathrm{CO}_{2}$ ) lend themselves to this type of analysis. The inverse approach presented here can be used to make estimates of the temporal variability of hemispheric loadings of certain long-lived chemical species for which long time-series observations are available.

\section{Appendix: A}

An approximate seasonal budget of global and hemisphereintegrated $\mathrm{CO}_{2}$ sources and sinks has been formulated from published sources in a similar way to the steady-state estimates of Gillette and Box (1986). The main sources of $\mathrm{CO}_{2}$ are phototrophic (plant) and heterotrophic (mainly soil) respiration, anthropogenic activities, biomass burning, and ocean outgassing at certain locations and seasons. The main sinks of $\mathrm{CO}_{2}$ are uptake by terrestrial vegetation and ocean uptake at certain locations and seasons. The net primary production of land vegetation was evaluated according to Fung et al. (1987) as applied by Kettle et al. (2002). Soil respiration (SR) was parameterized as:

$S_{R}=B Q_{10}^{T / 10} W$

where $T$ is soil temperature in $10^{\circ} \mathrm{C}$ (from Sellers et al., 1995), $Q_{10}$ is the temperature coefficient used to express the fractional increase in reaction rate resulting from a $10^{\circ} \mathrm{C}$ increase in temperature (taken as 1.5 from Heimann et al., 1998), $W$ is soil water content (from Sellers et al., 1995), and $B$ is an empirical constant that was calculated so that net primary production and soil respiration balance each other when integrated over one year. Anthropogenic $\mathrm{CO}_{2}$ input has been taken from the tabulated values of Rotty (1987). The $\mathrm{CO}_{2}$ contribution from biomass burning has been taken from the tabulated values of Hao and Liu (1994) using the emission factor of $40 \%$ from Levine (1994). The monthly global and hemispheric oceanic exchange of $\mathrm{CO}_{2}$ was based on the global flux fields of Wanninkhof et al. (2001) and Takahashi et al. (2002) and made available by T. Takahashi, R. Wanninkhof, and S. Sutherland (private communication, 2002).

Unlike the work of Gillette and Box (1986), there has been no correction of the $\mathrm{CO}_{2}$ fluxes to a standard year, and there has been no attempt to balance the different $\mathrm{CO}_{2}$ sources and sinks to obtain net fluxes that are consistent with the increasing $\mathrm{CO}_{2}$ mixing ratios. There are many experimental and modeling programs have been carried out to identify the sources and sinks of $\mathrm{CO}_{2}$ and to forecast its future growth (e.g. Houghton et al., 2001). The summary presented here only illustrates the main similarities and differences between the budgets of $\mathrm{COS}$ and $\mathrm{CO}_{2}$.
Acknowledgement. The authors gratefully acknowledge the published and unpublished digital information for total column COS data which were provided by T. Blumenstock (Izaña, Tenerife), E. Mahieu and R. Zander (Jungfraujoch), D. Griffith (Lauder and Wollongong), J. Notholt (Ny Ålesund, Spitsbergen), and C. Rinsland (Kitt Peak). The ground-based FTIR stations are part of NDSC (Network for the Detection of Stratospheric Change). We thank S. Sutherland, T. Takahashi, and R. Wanninkhof for making available the latest global fields of oceanic $\mathrm{CO}_{2}$ fluxes and $\mathrm{M}$. Lawrence and C. Brühl for providing $\mathrm{OH}$ radical and photolysis information. This work has been supported by the Natural Science and Engineering Research Council of Canada and the Max Planck Society of Germany.

\section{References}

Bingemer, H. G., Bürgermeister, S., Zimmermann, R. L., and Georgii, H.-W.: Atmospheric OCS: Evidence for a contribution of anthropogenic sources? J. Geophys. Res., 95, 20 617-20 622, 1990.

Bousquet, P., Ciais, P., Peylin, P., Ramonet, M., and Monfray, P.: Inverse modeling of annual atmospheric $\mathrm{CO}_{2}$ sources and sinks. 1. Method and control inversion, J. Geophys. Res., 104, $26161-$ $26178,1999$.

Chin, M. and Davis, D. D.: Global sources and sinks of OCS and $\mathrm{CS}_{2}$ and their distributions, J. Geophys. Res., 7, 321-337, 1993.

Crutzen, P. J.: The possible importance of OCS for the sulfate layer of the stratosphere, Geophys. Res. Lett., 3, 73-76, 1976.

Dentener, F., Feichter, J., and Jeuken, A. D.: Simulation of the transport of $\mathrm{Rn}^{222}$ using on-line and off-line global models at different horizontal resolutions: a detailed comparison with measurements, Tellus, 51B, 573-602, 1999.

Fung, I. Y., Tucker, C. J., and Prentice, K. C.: Application of Advanced Very High Resolution Radiometer vegetation index to study atmosphere-biosphere exchange of $\mathrm{CO}_{2}$, J. Geophys. Res., 92, 2999-3015, 1987.

Gillette, D. A. and Box, E. O.: Modeling seasonal changes of atmospheric carbon dioxide and carbon 13, J. Geophys. Res., 91, 5287-5304, 1986.

Griffith, D. W. T., Jones, N. B., and Matthews, W. A.: Interhemispheric ratio and annual cycle of carbonyl sulfide (OCS) total column from ground-based solar FTIR spectra, J. Geophys. Res., 103, 8447-8454, 1998.

Griffith, D. W. T., Meier, A., and Jones, N.: OCS above the Australian east coast and New Zealand, in NDSC (Network for the Detection of Stratospheric Change) 2001 Symposium: Celebrating 10 years of atmospheric research, Arcachon, France, 2001.

Hao, W. M. and Liu, M.-H.: Spatial and temporal distribution of tropical biomass burning, Global Biogeochem, Cycles, 8, 495503, 1994.

Heimann, M., Esser, G., Haxeltine, A., Kaduk, J., Kicklighter, D. W., Knorr, W., Kohlmeier, G. H., McGuire, A. D., Melillo, J., Moore, III, B., Otto, R. D., Prentice, I. C., Sauf, W., Schloss, A., Sitch, S., Wittenberg, U., and Würth, G.: Evaluation of terrestrial carbon cycle models through simulations of the seasonal cycle of atmospheric $\mathrm{CO}_{2}$ : First results of a model intercomparison study, Global Biogeochem. Cycles, 12, 1-24, 1998.

Houghton, J. T., Ding, Y., Griggs, D. J., Noguer, M., van der Linden, P. J., Dai, X., Maskell, K., and Johnson, C. A.: Climate 
Change 2001: The Scientific Basis. Cambridge University Press, Cambridge, 2001.

Keeling, C. D.: The carbon dioxide cycle: reservoir models to depict the exchange of atmospheric carbon dioxide with the oceans and land plants, in: Chemistry of the Lower Atmosphere, (Ed) Rasool, S. I., chap. 6. Plenum Press, New York, 1973.

Kettle, A. J.: Comparison of different dynamical models to predict the upper ocean concentration of a photochemical tracer as a function of depth and time, Mar. Freshwater Res., 51, 289-304, 2000.

Kettle, A. J., Kuhn, U., von Hobe, M., Kesselmeier, J., and Andreae, M. O.: The global budget of atmospheric carbonyl sulfide: Temporal and spatial variations of the dominant sources and sinks, J. Geophys. Res., accepted, 2002.

Kjellström, E.: A three-dimensional global model study of carbonyl sulfide in the troposphere and the lower stratosphere, J. Atmos. Chem., 29, 151-177, 1998.

Law, R. M., Rayner, P. J., Denning, A. S., Erickson, D., Fung, I. Y., Heimann, M., Piper, S. C., Ramonet, M., Taguchi, S., Taylor, J. A., Trudinger, C. M., and Watterson, I. G.: Variations in modeled atmospheric transport of carbon dioxide and the consequences for $\mathrm{CO}_{2}$ inversions, Global Biogeochem. Cycles, 10, 783-796, 1996.

Levine, J. S.: Biomass burning and the production of greenhouse gases, in: Climate Biosphere Interaction: Biogenic Emissions and Environmental Effects of Climate Change, (Ed) Zepp, R. G., chap. 9. John Wiley and Sons, 1994.

Logan, J. A.: An analysis of ozonesonde data for the lower stratosphere: recommendations for testing models, J. Geophys. Res., 104, 16 151-16 170, 1999.

Mahieu, E., Zander, R., Delbouille, L., Demoulin, P., Roland, G., and Servais, C.: Observed trends in total vertical column abundances of atmospheric gases from IR solar spectra recorded at the Jungfraujoch, J. Atmos. Chem, 28, 227-243, 1997.

Marquardt, D. W. and Acuff, S. K.: Direct quadratic spectrum estimation with irregularly spaced data, in: Time Series Analysis of Irregularly Observed Data, (Ed) Parzen, E., Lecture Notes in Statistics, 25, Springer-Verlag, New York, 1984.

Marufu, L., Dentener, F., Lelieveld, J., Andreae, M. O., and Helas, G.: Photochemistry of the African troposphere: Influence of biomass-burning emissions, J. Geophys. Res., 105, 14513$14530,2000$.

Mihalopoulos, N.: Contribution à l'étude du cycle biogéochimique de l'oxysulfure de carbone dans l'atmosphère, Ph.D. thesis, L'Université de Paris VII, Paris, 1989.

Mihalopoulos, N., Putaud, J. P., Nguyen, B. C., and Belviso, S.: Annual variation of atmospheric carbonyl sulfide in the marine atmosphere in the Southern Indian Ocean, J. Atmos. Chem., 13, 73-82, 1991.

Newell, R. E., Boer, G. J., and Kidson, J. W.: An estimate of the interhemispheric transfer of carbon monoxide from tropical general circulation data, Tellus, 26, 103-107, 1974.

Notholt, J., Toon, G., Stordal, F., Solberg, S., Schmidbauer, N., Becker, E., Meier, A., and Sen, B.: Seasonal variations of atmospheric trace gases in the high Arctic at $79^{\circ} \mathrm{N}$, J. Geophys. Res., 102, 12 855-12 861, 1997.

Plumb, R. A. and Zheng, X. Y.: Source determination from trace gas observations: an orthogonal function approach and results for long-lived gases with surface sources, J. Geophys. Res., 101,
18 569-18 585, 1996.

Press, W. H., Teukolsky, S. A., Vetterling, W. T., and Flannery, B. P.: Numerical Recipes in FORTRAN; The Art of Scientific Computing, Cambridge University Press, 1992.

Randerson, J. T., Thompson, M. V., Conway, T. J., Fung, I. Y., and Field, C. B.: The contribution of terrestrial sources and sinks to trends in the seasonal cycle of atmospheric carbon dioxide, Global Biogeochem. Cycles, 11, 535-560, 1997.

Read, P. L.: Applications of chaos to meteorology and climate, in: The Nature of Chaos, (Ed) Mullin, T., pp. 222-260. Clarendon Press, Oxford, 1993.

Rhodes, C., Riddel, S. A., West, J., Williams, B. P., and Hutchings, G. J.: The low-temperature hydrolysis of carbonyl sulfide and carbon disulfide: a review, Catalysis Today, 59, 443-464, 2000.

Rinsland, C. P., Zander, R., Mahieu, E., Demoulin, P., Goldman, A., Ehhalt, D. H., and Rudolph, J.: Ground-based infrared measurements of carbonyl sulfide total column abundances: Long-term trends and variability, J. Geophys. Res., 97, 5995-6002, 1992.

Rodhe, H.: Human impact on the atmospheric sulfur balance, Tellus, A-B, 51, 110-122, 1999.

Rotty, R. M.: Estimates of seasonal variations in fossil fuel $\mathrm{CO}_{2}$ emissions, Tellus B, 39, 184-202, 1987.

Schneider, M.: Continuous observations of atmospheric trace gases by ground-based FTIR spectroscopy at Izaña Observatory, Tenerife Island, Ph. D. thesis, University of Karlsruhe, FZKA Report 6727, Forschungszentrum Karlsruhe, 2002.

Seinfeld, J. H. and Pandis, S. N.: Atmospheric Chemistry and Physics, John Wiley and Sons, New York, 1998.

Sellers, P. J., Meeson, B. W., Hall, F. G., Asrar, G., Murphy, R. E., Schiffer, R. A., Bretherton, F. P., Dickinson, R. E., Ellingson, R. G., Field, C. B., Huemmrich, K. F., Justice, C. O., Melack, J. M., Roulet, R. T., Schimel, D. S., and Try, P. D.: Remote sensing of the land surface for studies of global change: models - algorithms - experiments, Remote Sens. Environ., 51, 3-26, 1995.

Stull, R. B.: An Introduction to Boundary Layer Meteorology, Kluwer Academic Publishers, Dordrecht, 1988.

Sturges, W. T., Penkett, S. A., Barnola, J.-M., Chappellaz, J., Atlas, E., and Stroud, V.: A long-term record of carbonyl sulfide (COS) in two hemispheres from firn air measurements, Geophys. Res. Lett., 28, 4095-4098, 2001.

Takahashi, T., Sutherland, S. G., Sweeney, C., Poisson, A. P., Metzl, N., Tilbrook, B., Bates, N. R., Wanninkhof, R. H., Feely, R. A., Sabine, C. L., Olafsson, J., and Nojiri, Y.: Global sea-air $\mathrm{CO}_{2}$ flux based on climatological sea surface ocean $\mathrm{pCO}_{2}$, and seasonal biological and temperature effects, Deep Sea Res. II, 49, 1601-1622, 2002.

Tans, P. P., Fung, I. Y., and Takahashi, T.: Observational constraints on the global atmospheric $\mathrm{CO}_{2}$ budget, Science, 247, 14311438, 1990.

Thuburn, J. and Craig, G. C.: GCM tests of theories of the height of the tropopause, J. Atmos. Sci., 54, 869-882, 1997.

Thuburn, J. and Craig, G. C.: Stratospheric influence on tropopause height: The radiative constraint, J. Atmos. Sci., 57, 17-28, 2000.

Torres, A. L., Maroulis, P. J., Goldberg, A. B., and Bandy, A. R.: Atmospheric OCS measurements on Project Gametag, J. Geophys. Res., 85, 7357-7360, 1980.

Ulshöfer, V. S. and Andreae, M. O.: Carbonyl sulfide (COS) in the surface ocean and the atmospheric COS budget, Aquatic 
Geochem., 3, 283-303, 1998.

Wanninkhof, R., Doney, S. C., Takahashi, T., and McGillis, W. R.: The effect of using time-averaged winds on regional air-sea $\mathrm{CO}_{2}$ fluxes, in: Gas Transfer at Water Surfaces, Geophysical Monograph 127, (Eds) Donelan, M., Drennan, W., Saltzman, E., and Wanninkhof, R., pp. 351-357. AGU, Washington, D. C., 2001.

Watts, S. F.: The mass budgets of carbonyl sulfide, dimethyl sulfide, carbon disulfide and hydrogen sulfide, Atmos. Environ., 34, 761$779,2000$.
$\mathrm{Xu}, \mathrm{X}$. : Investigations into the tropospheric cycle of COS: atmospheric distribution, air-sea and air-vegetation exchanges, Ph.D. thesis, Johann Wolfgang Goethe-Universit"at, Frankfurt am Main, 2000.

Xu, X., Bingemer, H. G., Georgii, H.-W., Schmidt, U. and Bartell, U.: Measurements of carbonyl sulfide (COS) in surface seawater and marine air, and estimates of the air-sea flux from observations during two Atlantic cruises, J. Geophys. Res., 106, 34913502, 2001. 